\title{
Bank Runs, Portfolio Choice, and Liquidity Provision
}

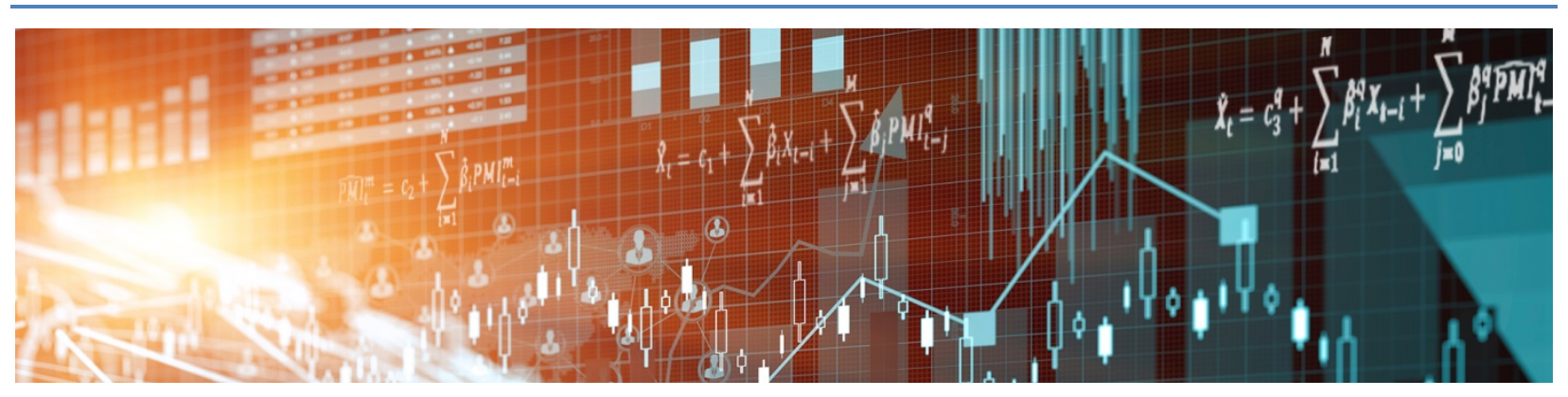

by Toni Ahnert and Mahmoud Elamin 
Bank of Canada Staff Working Paper 2019-37

September 2019

\title{
Bank Runs, Portfolio Choice, and Liquidity Provision
}

\author{
by \\ Toni Ahnert ${ }^{1}$ and Mahmoud Elamin \\ ${ }^{1}$ Financial Stability Department \\ Bank of Canada \\ Ottawa, Ontario, Canada K1A 0G9 \\ tahnert@bankofcanada.ca
}




\section{Acknowledgements}

This paper supersedes "The Effect of Safe Assets on Financial Fragility in a Bank-Run Model." We thank Jason Allen, Falko Fecht, Itay Goldstein, Joseph Haubrich, Shota Ichihashi, Agnese Leonello, Sergio Vicente, and seminar audiences at the $27^{\text {th }}$ Finance Forum 2019, Amsterdam (UvA), Cleveland Fed, Cleveland State, Finance Theory Group Summer School 2015, FIRS 2014, Ames Global Games Workshop 2016, Lisbon Meetings in Game Theory and Applications 2016, MidWest Economic Theory 2015, Midwest Finance 2016, Pittsburgh, and San Francisco Fed for comments. All remaining errors are ours. Duncan Whyte provided excellent research assistance. These are our views and are not necessarily those of the Bank of Canada. 


\begin{abstract}
We examine the portfolio choice of banks in a micro-funded model of runs. To insure riskaverse investors against liquidity risk, competitive banks offer demand deposits. We use global games to link the probability of a bank run to the portfolio choice. Based upon interim information about risky investment, banks liquidate investments to hold a safe asset. This partial hedge against investment risk reduces the withdrawal incentives of investors for a given deposit rate. As a result of the portfolio choice, (i) banks provide more liquidity ex ante (so banks offer a higher deposit rate), and (ii) the welfare of investors increases.
\end{abstract}

Bank topics: Financial institutions; Financial stability; Wholesale funding

JEL codes: G01, G21 


\section{Introduction}

Safe assets comprise a sizable share of bank assets. Figure 1 shows the time series of the share of safe assets averaged over U.S. banks in the period 2000-16, with an average of $15 \%$. Active management of this share results in significant time variation, with a standard deviation of $2.1 \%$. Turning to microdata in the cross-section, Cornett et al. (2011) examine individual bank behavior during the recent financial crisis. They find that banks with more exposure to risk increased their holdings of safe assets. The active management of a bank's share of safe assets is at the heart of this paper.

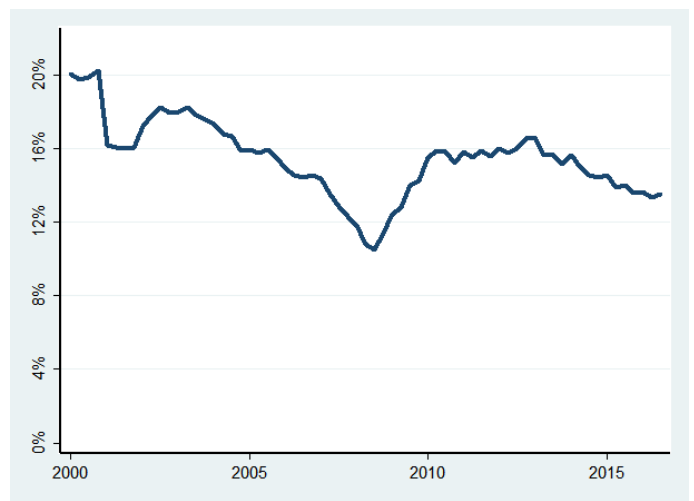

Figure 1: Safe asset share of U.S. banks in the period 2000-16 (Federal Reserve Y-9C).

Demand deposits insure risk-averse investors against idiosyncratic liquidity shocks but expose banks to runs (Diamond and Dybvig (1983), henceforth DD). Introducing investment risk and incomplete information, Goldstein and Pauzner (2005) (GP) endogenize the bank-run probability and show that it increases in the bank's liquidity provision. Since a competitive bank balances its liquidity provision with endogenous run risk, liquidity risk sharing is below its first-best level. While investors are protected against liquidity risk via demand deposits, they are fully exposed to investment risk in GP. In this paper, we introduce safe assets as a partial hedge against investment risk. We show that this interim portfolio choice reduces the withdrawal incentives of investors and raises both bank liquidity provision and investor welfare. 
We introduce portfolio choice to Goldstein and Pauzner (2005)'s micro-founded model of bank runs. As in DD, risk-averse investors face unobservable idiosyncratic liquidity shocks, and competitive banks offer a deposit contract that allows for interim withdrawals. As in GP, investment is risky and can be liquidated before maturity. Investors receive dispersed private information about the unobserved investment risk upon which they base their withdrawal decisions. This signal informs investors about both investment risk and the possible signals of other investors. Adding to GP's available technologies, we allow the bank to hold safe assets upon liquidating investment. The bank observes investment risk and holds a portfolio of risky and safe assets.

This embedded standard portfolio choice expands the contract offered to investors. It now comprises two parts. The first is the usual non-contingent deposit rate promised upon withdrawal. The second part is novel. The bank specifies interim safe asset holdings contingent on investment risk. This contract is consistent with the observation that a bank sets non-contingent interest rates on deposits and other fixed-rate short-term funding but adjusts its portfolio composition as new information arrives. We focus on private contracts and abstract from government interventions.

Our main contribution is to show how bank portfolio choice affects the withdrawal incentives of investors, bank liquidity provision, and investor welfare. The portfolio choice allows the bank to transfer resources from the good state to the bad state (in which investment fails). This reallocation partially hedges non-withdrawing patient investors against investment risk, providing them with the proceeds from safe assets in the bad state. ${ }^{1}$ The interim portfolio choice between risky investment and safe assets complicates the analysis, but we adapt the approach of GP based on one-sided strategic complementarity to our environment.

\footnotetext{
${ }^{1}$ When marginal utility at zero is high enough, a solvent bank always liquidates some risky investment to hold safe assets. This natural assumption about the marginal utility is implied by Inada conditions, for example. Allen and Gale (1998) impose a similar lower bound on marginal utility at zero in a bank portfolio problem without coordination risk.
} 
The unique equilibrium is in threshold strategies. Patient investors withdraw if and only if their private signal is below a threshold. The patient investor who receives the equilibrium threshold as his signal is indifferent between withdrawing and not withdrawing. An insolvent bank fully liquidates and does not hold safe assets, so the expected utility of investors is independent of safe assets. In contrast, a solvent bank always holds safe assets. In this case, a withdrawing investor receives the promised deposit rate and his expected utility is independent of safe assets. A nonwithdrawing investor, however, benefits from the partial hedge against investment risk and his expected utility is higher with safe assets. Therefore, investors withdraw for fewer realizations of investment risk and both the withdrawal threshold and the run probability decrease for a given deposit rate.

We turn to the ex-ante implications of lower withdrawal incentives because of the partial hedge against investment risk. We show that safe asset holdings result in uniformly higher investor welfare. Investors benefit from (i) a higher expected utility when the bank is solvent because of the partial hedge, and (ii) a lower withdrawal threshold for any given deposit rate. Turning to the equilibrium level of the deposit rate, GP show that the liquidity provision of banks is below its first-best level because of the detrimental effect of the deposit rate on the probability of a bank run. When safe asset holdings mitigate the incentives to withdraw, however, the marginal cost of liquidity provision is lower and competitive banks increase their liquidity provision to investors, better insuring against liquidity risk.

Our technical contribution to the global-games literature is to extend the methods of GP to the more complicated environment with bank portfolio choice. We show that the properties of the net incentives for withdrawing, the one-sided strategic complementarity, and equilibrium uniqueness extend to our setting in which interim portfolio choice results in additional effects of the economic fundamental and the withdrawal proportion. The interested reader is referred to the main text for details. 
Literature. Most global-games literature on bank runs makes additional assumptions to obtain global strategic complementarities; that is, the incentives to run on the bank increase in the proportion of those who run, irrespective of whether the bank is solvent or insolvent. Examples include Morris and Shin (2000), who make specific assumptions about preferences and technology, and Rochet and Vives (2004), Vives (2014), Ahnert and Kakhbod (2017), and Ahnert et al. (2019), who assume that the rollover decision is delegated to fund managers with exogenous payoffs. Goldstein and Pauzner (2005) differs from most literature by micro-founding the payoffs. Focusing on the payoffs of investors complicates the analysis, however, and results in strategic complementarity that is only one-sided. An investor's incentive to run increases in the proportion of running investors when the bank is solvent and decreases in this proportion when the bank is insolvent. Introducing safe assets complicates the analysis further, but we show that one-sided strategic complementarity still holds.

We share with Allen and Gale (1998) the hedging motive against investment risk via safe asset holdings and interim information about the future profitability of investment. Studying the optimal portfolio choice and efficient risk-sharing in a DD model with illiquid investment, they show that a bank run can be optimal by improving risk sharing with early consumers for a standard deposit contract. There are two differences. First, their result on the efficiency of (partial) bank runs relies on the perfect illiquidity of investment, while we follow DD and consider liquid investment. Second, their banks select the preferred equilibrium when multiple equilibria exist, while we use global games to uniquely pin down the withdrawal behavior of investors.

Our paper is also related to the literature on bank liquidity management. Following DD, Cooper and Ross (1998) and Ennis and Keister (2006) study the initial portfolio choice of a competitive bank with costly liquidation, sun-spot runs, and safe investment. They show that a higher run probability reduces (increases) safe asset holdings for small (large) liquidation costs. There are two differences. First, the 
benefit of safe assets in our model is insurance against investment risk, not avoiding costly liquidation. Second, we use a global-games approach to obtain an endogenous run probability and link it to the demand-deposit contract and bank portfolio choice.

A closely related paper is Allen et al. (2018), who study government guarantees in the environment of GP. Since risk-averse investors seek protection against both liquidity and investment risk, a government guarantee can reduce fragility and increase liquidity provision by banks. In contrast to their paper, we focus on the purely private arrangement and study how safe asset holdings of banks reduce fragility and increase bank liquidity provision and investor welfare. Eisenbach (2017) studies the role of short-term debt to discipline bankers subject to risk-shifting incentives. Shortterm debt is an efficient disciplining device when risk is idiosyncratic, but a two-sided inefficiency arises for aggregate risk. While Eisenbach (2017) studies the maturity choice on the bank's liability side, we study the portfolio choice on its asset side.

In another global-games paper, Liu and Mello (2011) study the optimal cash holdings of hedge funds subject to aggregate liquidity shocks and redemptions of risk-neutral investors. Cash forgoes a higher safe investment return but avoids costly interim liquidation and sometimes reduces the fragility of the fund. In contrast, safe asset holdings in our model partially hedge risk-averse investors against aggregate investment risk and unambiguously reduce the fragility of banks.

We emphasize the interim portfolio choice of banks. In the model, there is no role for initial safe asset holdings because interim liquidation of investment at par yields the same return as safe assets. Therefore, we focus on the non-trivial interim portfolio choice when safe assets partially hedge risk-averse investors against investment risk. ${ }^{2}$ Our approach is consistent with the evidence in Morris et al. (2016),

\footnotetext{
${ }^{2}$ Our results are unchanged if both initial and interim portfolio choice is feasible because investment is costless to liquidate in our model and in GP. If only an initial portfolio choice were feasible, however, the welfare of investors would be lower because a bank's safe asset holdings cannot be contingent on investment risk and withdrawals.
} 
who show that asset managers hoard cash after redemptions. In their model and in Zeng (2016), such cash hoarding serves as a precautionary motive against future redemptions. In contrast, safe asset holdings in our model insure risk-averse investors against investment risk and affect the redemption decision of remaining investors.

The remainder of the paper proceeds as follows. We present a bank-run model with interim portfolio choice in section 2. We study its equilibrium in section 3, examining the impact of safe assets holdings on investor withdrawal incentives, bank liquidity provision, and investor welfare. In section 4 , we discuss an assumption about interim information. All proofs are in the appendices.

\section{Model}

We study the portfolio choice of banks in the global-games model of runs by Goldstein and Pauzner (2005). There are three dates: initial $(t=0)$, interim $(t=1)$, and final $(t=2)$. A single good is used for consumption and investment. The economy consists of a continuum of investors, $i \in[0,1]$, each with a unit endowment at $t=0$. As in Diamond and Dybvig (1983), an investor privately learns his individual preference for consumption $\omega_{i} \in\{0,1\}$ at $t=1$. An impatient investor, $\omega_{i}=1$, values consumption only at the interim date, while a patient investor, $\omega_{i}=0$, values it at the interim and the final dates:

$$
U_{i}\left(c_{1}, c_{2}\right)=\omega_{i} u\left(c_{1}\right)+\left(1-\omega_{i}\right) u\left(c_{1}+c_{2}\right),
$$

where $c_{t}$ is consumption at date $t$. The probability of being impatient, $\operatorname{Pr}\left\{\omega_{i}=1\right\} \equiv$ $\lambda \in(0,1)$, is i.i.d. across investors and equals the proportion of impatient investors at $t=1$ by a law of large numbers. The utility function $u(c)$ is twice continuously differentiable, strictly increasing, strictly concave, and satisfies $u(0) \equiv 0 .{ }^{3}$

\footnotetext{
${ }^{3}$ This normalization follows GP and is without loss of generality if the utility at zero is bounded.
} 
A constant-return-to-scale investment technology is available at $t=0$. It matures at $t=2$ but can be liquidated at par at $t=1$. As in GP, but in contrast to DD, investment is risky with a return $R>1$ if successful (good state) and zero otherwise (bad state). An economic fundamental $\theta$ determines the probability of success $p(\theta)$, a continuously differentiable and strictly increasing function, $p^{\prime}(\theta)>0$. The net present value of investment at $t=0$ is positive in expected utility terms, $E_{\theta}[p(\theta)] u(R)>u(1)$.

Our emphasis is on the portfolio choice at the interim date. A safe asset (storage technology) is available at $t=1$ and yields a return at $t=2$ normalized to one. As in DD and GP, liquidation of investment at $t=1$ at par eliminates a role for a safe asset at $t=0$. A bank invests all resources at $t=0$ and liquidates at $t=1$ to satisfy withdrawals. Liquidation at $t=1$ has an additional role in our model, however. Banks liquidate to hold safe assets as a partial hedge against investment risk.

There is incomplete information among investors about the fundamental. It is drawn from a uniform distribution, $\theta \sim U[0,1]$, but is not publicly observed. Each investor receives a noisy private signal at $t=1, \theta_{i} \equiv \theta+\epsilon_{i}$, where the idiosyncratic noise is independent of the fundamental and i.i.d. across investors, $\epsilon_{i} \sim U[-\epsilon, \epsilon]$, for some $\epsilon>0$. We assume that the bank observes the realized fundamental $\theta$ at $t=1$. $^{4}$

At $t=0$, a bank offers a contract to maximize investor expected utility because of free entry (Allen and Gale, 2007). The portfolio choice expands the contract that now comprises two parts. The first specifies a non-contingent deposit rate $r_{1}>$ 1 to investors who withdraw, as in DD and GP. By pooling resources, the bank insures investors against liquidity risk. Upon observing their private information at $t=1$, investors simultaneously decide whether to withdraw, where $n \in[\lambda, 1]$ is the withdrawal proportion. For low withdrawals, $n \leq \frac{1}{r_{1}}$, the bank is solvent and serves all withdrawals. For high withdrawals, $n>\frac{1}{r_{1}}$, the bank is insolvent and a withdrawing investor receives $r_{1}$ with probability $\frac{1}{n r_{1}}$ and zero otherwise (sequential service).

\footnotetext{
${ }^{4}$ For a discussion of this assumption, please see section 4.
} 
The second part of the contract is novel. It represents an embedded standard portfolio problem (Arrow, 1963; Pratt, 1964). A solvent bank at $t=1$ has remaining investments per non-withdrawing investor, $\frac{1-n r_{1}}{1-n}>0$, that depend on the withdrawal volume $n$ and bank liquidity provision $r_{1}$. Contingent on the investment risk $\theta$ faced by these investors, the bank chooses how much of the remaining investment to liquidate in order to hold the safe asset and partially hedge against investment risk. An investor who does not withdraw at $t=1$ receives an equal share of the bank's assets at $t=2$, which comprise the proceeds from both investment and the safe asset.

\begin{tabular}{lll}
\hline Initial date $t=0$ & Interim date $t=1$ & Final date $t=2$ \\
\hline $\begin{array}{l}\text { 1. Bank offers demand- } \\
\text { deposit contract. }\end{array}$ & $\begin{array}{c}\text { 1. Private information } \\
\text { about investment. }\end{array}$ & $\begin{array}{c}\text { 1. Investment and safe } \\
\text { asset mature. }\end{array}$ \\
$\begin{array}{c}\text { 2. Investors deposit } \\
\text { their endowment. }\end{array}$ & $\begin{array}{l}\text { 2. Investors withdraw. } \\
\text { 3. Bank liquidates investment } \\
\text { to serve withdrawals } \\
\text { and hold a safe asset. }\end{array}$ & 2. Investors withdraw. \\
& 4. Consumption. \\
\hline
\end{tabular}

Table 1: Timeline of events.

\section{Equilibrium}

We solve for the perfect Bayesian equilibrium in pure strategies. The bank chooses from a set of contracts, where a contract specifies (i) a promised deposit rate $r_{1}$, and (ii) a menu of interim safe asset holdings $y\left(\theta, n, r_{1}\right)$ for each realized fundamental $\theta$, withdrawal proportion $n$, and deposit rate $r_{1}$. Any deposit rate $r_{1}$ defines a withdrawal subgame at $t=1$. In this subgame, the fundamental $\theta$ is realized and determines the signals $\left\{\theta_{i}\right\}$ that investors receive. Based on these signals, investors simultaneously 
decide whether to withdraw, which determines the withdrawal proportion $n$. Based on this proportion and the fundamental, a solvent bank liquidates, serves withdrawals, and holds the remaining liquidation proceeds in the safe asset.

We work backward to construct the equilibrium. First, we derive and characterize the optimal safe asset holdings, $y^{*}\left(\theta, n, r_{1}\right)$, in section 3.1. Safe asset holdings affect investor withdrawal decisions and the deposit rate. In section 3.2, we then study the dominance regions required for the global-games analysis. Third, we derive the optimal withdrawal decisions and withdrawal proportion $n^{*}\left(\theta ; r_{1}\right)$ in section 3.3. Finally, we derive the optimal deposit rate $r_{1}^{*}$ in section 3.4. We compare our results with the benchmark without portfolio choice (GP) throughout.

\subsection{Portfolio choice}

The safe asset holding problem is similar to the classic portfolio problem in which a risk-averse investor with some wealth chooses a portfolio of risky and safe assets. Investment risk is determined by the fundamental $\theta$, where a higher $\theta$ corresponds to a first-order stochastic dominance improvement in the investment return. After $n$ investors withdraw, a solvent bank has $\frac{1-n r_{1}}{1-n}>0$ of investment per non-withdrawing investor. The bank maximizes investor expected utility at $t=1$ by liquidating investment to hold safe assets per non-withdrawing investor $y .{ }^{5}$ Safe assets shift consumption from the good state, $R\left[\frac{1-n r_{1}}{1-n}-y\right]+y$, to the bad state, $y$, insuring against investment risk. If insolvent, a bank fully liquidates, and there is no role for safe assets. By contrast, a solvent bank solves the following problem for all $\left(n, r_{1}, \theta\right)$ :

$y^{*}\left(\theta, n, r_{1}\right) \equiv \arg \max _{y \in\left[0, \frac{1-n r_{1}}{1-n}\right]} U(y) \equiv p(\theta) u\left(R\left[\frac{1-n r_{1}}{1-n}\right]-(R-1) y\right)+(1-p(\theta)) u(y)$

\footnotetext{
${ }^{5}$ Like investment per non-withdrawing investor, $\frac{1-n r_{1}}{1-n}>0$, safe asset holdings are measured per non-withdrawing investor, so the total volume of safe assets are $y(1-n) \in\left[0,1-n r_{1}\right]$.
} 
where consumption levels are equalized across states at $y=\frac{1-n r_{1}}{1-n}$. Proposition 1 characterizes the bank's safe asset holdings at the interim date.

Proposition 1. Portfolio choice. The interim safe asset holdings $y^{*}$ are unique.

1. If $\theta \leq \underset{\sim}{\theta}$ defined by $p(\underline{\theta}) R \equiv 1$, then the bank fully liquidates, $y^{*}=\frac{1-n r_{1}}{1-n}$.

2. If $p(\theta)=1$, then the investment is not risky and no liquidation occurs, $y^{*}=0$.

3. If $\theta>\underset{\sim}{\theta}, p(\theta)<1$, and $u^{\prime}(0)>\frac{p(R-1)}{1-p} u^{\prime}\left(R \frac{1-n r_{1}}{1-n}\right)$, then liquidation is partial:

$$
(1-p(\theta)) u^{\prime}\left(y^{*}\right)=p(\theta)(R-1) u^{\prime}\left(\frac{1-n r_{1}}{1-n} R-y^{*}(R-1)\right)
$$

Safe asset holdings $y^{*} \in\left(0, \frac{1-n r_{1}}{1-n}\right)$ decrease in liquidity provision $\left(\frac{\partial y^{*}}{\partial r_{1}}<0\right)$, the proportion of withdrawing investors $\left(\frac{\partial y^{*}}{\partial n}<0\right)$, and the fundamental $\left(\frac{\partial y^{*}}{\partial \theta}<0\right)$.

\section{Proof. See Appendix A.}

A unique safe asset holding $y^{*}$ is ensured by the concavity of the utility function. When investment risk is absent (e.g., when the fundamental $\theta$ is in the upper dominance region - see below), then there is no role for a hedge, so $y^{*}=0$. Otherwise, safe asset holdings are positive for a sufficiently high enough marginal utility of consumption at zero. Hereafter, we assume that this condition holds, which is quite common in banking theory (e.g., Diamond and Dybvig (1983) and Allen and Gale (1998)). ${ }^{6}$ When the realized fundamental is low, the interim net present value of investment is negative in expected utility terms, so the bank fully liquidates. When the fundamental is intermediate, liquidation is only partial, $y^{*}<\frac{1-n r_{1}}{1-n}$. Safe assets provide risk-averse investors with insurance against investment risk but forgo profitable investment and the marginal cost and marginal benefit are balanced in equilibrium.

\footnotetext{
${ }^{6}$ For example, the augmented CRRA utility function $u(c)=\frac{(c+\psi)^{1-\gamma}-\psi^{1-\gamma}}{1-\gamma}$ satisfies $u(0)=0$. Moreover, the marginal utility at zero, $u^{\prime}(0)=\psi^{-\gamma}$, is finite but arbitrarily large for small $\psi$.
} 
We turn to the comparative statics of safe asset holdings. Both higher liquidity provision by banks and a larger withdrawal proportion of investors reduce the funds available for non-withdrawing investors, $\frac{1-n r_{1}}{1-n} \cdot{ }^{7}$ Therefore, safe asset holdings fall in order to spread resources more evenly across the good and bad states. Intuitively, when overall resources per capita are scarcer, the amount per capita transferred from the good state to the bad state is lower.

A better economic fundamental $\theta$ reduces investment risk in a first-order stochastic dominance sense, so intuitively the hedge against investment risk also falls. The expected benefit in terms of a partial hedge is lower, while the expected cost in terms of forgoing investment is higher. This result is consistent with the evidence provided in Cornett et al. (2011) mentioned in the introduction.

In Appendix A, we state and prove three useful technical results: the optimal expected utility, $U\left(y^{*}\right)$, decreases in both the withdrawal proportion $n$ (Lemma 1 ) and the deposit rate $r_{1}$ (Lemma 2) but increases in the fundamental $\theta$ (Lemma 3). These results help us establish dominance regions and one-sided strategic complementarity.

\subsection{Dominance regions}

As is typical in the global-games literature, we make assumptions about dominance regions. When investors are certain that the fundamental is in these regions, they act regardless of the strategies or information of other investors (Morris and Shin, 2003).

As in GP, we assume an upper dominance region in all subgames, $\bar{\theta} \in(0,1)$. When the fundamental is in $[\bar{\theta}, 1]$, the liquidation value is $R$ and investment always succeeds, $p(\theta)=1$. We assume $\bar{\theta}<1-2 \epsilon$, so this region can shrink to a point, $\bar{\theta} \rightarrow 1$, as $\epsilon \rightarrow 0$. No safe assets are held for $\theta \geq \bar{\theta}$ as investment is safe (Proposition 1 ).

\footnotetext{
${ }^{7} \mathrm{~A}$ higher withdrawal proportion decreases available resources, $\frac{d \frac{1-n r_{1}}{1-n}}{d n}=\frac{1-r_{1}}{(1-n)^{2}}<0$, as $r_{1}>1$.
} 
We assume that the lowest fundamental leads to certain failure, $p(0)=0$. This natural assumption guarantees the existence of a non-trivial lower dominance region $\left[0, \underline{\theta}\left(r_{1}\right)\right]$ in all relevant subgames, $1<r_{1}<\frac{R}{1+\lambda(R-1)}<\min \left\{\frac{1}{\lambda}, R\right\}$. For a fundamental in the lower dominance region, $\theta<\underline{\theta}$, a patient investor has a strictly dominant action to withdraw (even if all patient investors do not, $n=\lambda$ ). In subgames with $r_{1} \geq \frac{R}{1+\lambda(R-1)}$, all fundamentals are in the lower dominance region, $\underline{\theta}=1$ because $r_{1} \geq \frac{R}{1+\lambda(R-1)}$ implies $u\left(\frac{1-\lambda r_{1}}{1-\lambda} R\right) \leq u\left(r_{1}\right)$, for all $p(\theta) \leq 1$, so a patient investor always withdraws. ${ }^{8}$ But $\underline{\theta}=1$ leaves no space for upper dominance and intermediate regions. In contrast, subgames with $1<r_{1}<\frac{R}{1+\lambda(R-1)}$ have $\underline{\theta} \in(0,1)$ and thus space for the upper dominance region and an intermediate region for small enough $\epsilon$.

Proposition 2. Lower dominance region. Consider a subgame defined by the deposit rate $r_{1} \in\left(1, \frac{R}{1+\lambda(R-1)}\right)$. If $p(0)=0$, there exists a non-trivial lower dominance bound, $\underline{\theta}\left(r_{1}\right)>0$. It increases in $r_{1}$ and converges to $\underline{\theta}(1)>0$ and $\underline{\theta}\left(\frac{R}{1+\lambda(R-1)}\right)=1$.

Proof. See Appendix B.

\subsection{Investor withdrawals}

This section contains several results. Proposition 3 states that the unique equilibrium in each subgame is in symmetric threshold strategies for some positive noise $\epsilon>0$. Its proof extends GP's proof to the case of safe asset holding. Uniqueness at every noise level does not guarantee a unique limit as noise vanishes, however. Proposition 4 states the continuity of the threshold with respect to noise, which guarantees a unique limit. Proposition 5 confirms that a higher deposit rate increases the withdrawal threshold and the probability of a bank run. Proposition 6 shows that introducing portfolio choice and allowing for safe asset holdings reduces the withdrawal threshold.

\footnotetext{
${ }^{8}$ In other words, the incentive compatibility constraint of patient investors is violated, which results in certain runs.
} 
An investor's strategy is a withdrawal probability for each realized signal $\theta_{i}$ in every subgame. In a given subgame $r_{1}$, an investor's utility is determined by the realized fundamental $\theta$ and the withdrawal proportion $n$. The strategies of other investors affect the utility function only through the withdrawal proportion $n$ and do not enter it directly. For each withdrawal proportion and fundamental, an investor's net incentive $v(\theta, n)$ is the utility differential between not withdrawing and withdrawing. The net incentive is affected by $n$ through the bank's solvency and expected utility in both solvency and insolvency. It is affected by $\theta$ via the expected utility when the bank is solvent, the success probability $p(\theta)$. The bank's portfolio choice, $y^{*}=y^{*}\left(\theta, n ; r_{1}\right)$, introduces additional channels of how $(\theta, n)$ affect net incentives:

$$
v(\theta, n)= \begin{cases}(1-p) u\left(y^{*}\right)+p u\left(\frac{1-n r_{1}}{1-n} R-(R-1) y^{*}\right)-u\left(r_{1}\right) & \lambda \leq n<\frac{1}{r_{1}} \\ -\frac{1}{n r_{1}} u\left(r_{1}\right) & \text { if } \\ & \frac{1}{r_{1}} \leq n \leq 1\end{cases}
$$

Bank solvency is governed by the withdrawal proportion. The bank is solvent whenever $\lambda \leq n<\frac{1}{r_{1}}$. Withdrawing yields $u\left(r_{1}\right)$ if the bank is solvent and $\frac{u\left(r_{1}\right)}{n r_{1}}$ otherwise because the probability of being served in insolvency is $\frac{1}{n r_{1}}$ (sequential service). Not withdrawing yields $(1-p(\theta)) u\left(y^{*}\right)+p(\theta) u\left(\frac{1-n r_{1}}{1-n} R-(R-1) y^{*}\right)$ if the bank is solvent and zero otherwise. Without safe assets, the net incentive collapses to GP's expression. ${ }^{9}$

Figure 2 shows the effect of safe asset holdings on the net incentive and the single crossing and the one-sided strategic complementarity properties. When the bank is solvent, $\lambda \leq n<\frac{1}{r_{1}}$, the net incentive $v$ is higher with safe asset holdings and decreases in $n$ (Lemma 1). For each $\theta$, the net incentive crosses zero at exactly one $n$. When the bank is insolvent, the net incentive increases in $n$, exactly as in GP.

\footnotetext{
${ }^{9}$ In the upper dominance region, $\theta \geq \bar{\theta}$, the net incentive is $u\left(\frac{R-n r_{1}}{1-n}\right)-u\left(r_{1}\right)$ if $n<1$ and $u(R)-u\left(r_{1}\right)$ if $n=1$. See also section 3.2.
} 


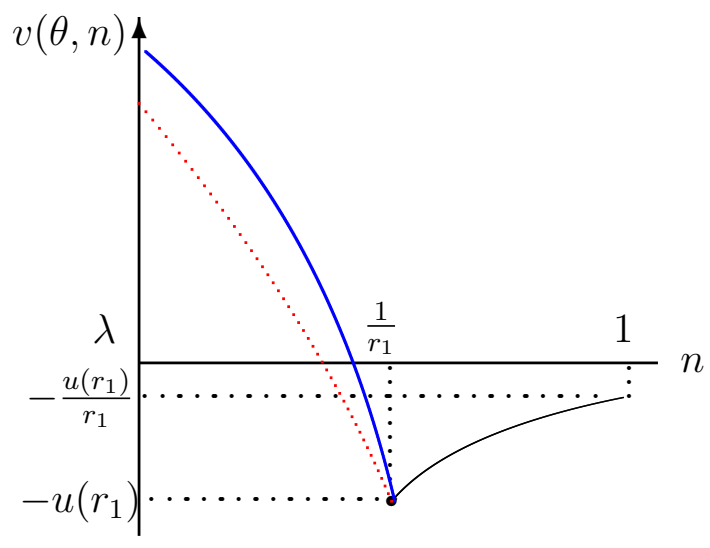

Figure 2: Net incentive $v(\theta, n)$ for fixed fundamental $\theta$ as the withdrawal proportion $n$ varies: with safe asset holdings (solid blue) and without (dotted red). Safe asset holdings increase the net incentive when the bank is solvent and have no effect otherwise. One-sided strategic complementarity and single crossing are preserved.

The realized fundamental $\theta$ determines the private signals of investors. Investor $i$ uses $\theta_{i}$ to extract information about the fundamental aspect $(\theta)$ and the strategic aspect (the possible signals of other investors). The posterior about $\theta$ is uniform and centered at the signal, $\left[\theta_{i}-\epsilon, \theta_{i}+\epsilon\right]$. An impatient investor always withdraws at $t=1$. A patient investor, however, compares the expected utility of withdrawing and not withdrawing. An equilibrium defines a mapping between the fundamental $\theta$ and the withdrawal proportion $n$ that goes through the signal structure and equilibrium strategies. These strategies determine the equilibrium withdrawal proportion.

Proposition 3. Uniqueness in each withdrawal subgame. Consider the withdrawal subgame defined by an deposit rate $r_{1} \in\left(1, \frac{R}{1+\lambda(R-1)}\right)$. There exists an upper bound on private noise $\bar{\epsilon}\left(r_{1}\right)>0$ such that, for all $0<\epsilon<\bar{\epsilon}$, there exists a unique threshold $\theta_{\epsilon}^{*}\left(r_{1}\right)$. A patient investor withdraws if and only if $\theta_{i}<\theta_{\epsilon}^{*}\left(r_{1}\right)$.

Proof. See Appendix C.

Proposition 3 shows that the unique equilibrium is a symmetric threshold equi- 
librium, $\theta^{*}$. This equilibrium induces a simple mapping between $\theta$ and $n$, where the withdrawal proportion is pinned down as a function of the fundamental, $n(\theta)$. The withdrawal proportion is determined by the proportion of investors who receive signals below the threshold, $\theta_{i} \leq \theta^{*}$. An investor who knows $\theta$ can compute $n$. When the fundamental is above $\theta^{*}+\epsilon$, all investors receive signals above the threshold and no patient investor withdraws, $n=\lambda$. When the fundamental is below $\theta^{*}-\epsilon$, every investor receives a signal below the threshold and all patient investors withdraw, $n=1$. In the intermediate region $\left[\theta^{*}-\epsilon, \theta^{*}+\epsilon\right]$, the proportion of investors with signals below the threshold linearly decreases in $\theta$, so $n$ decreases linearly between 1 and $\lambda$. The function $n(\theta)$ allows us to express the expected utility as $v(\theta) \equiv v(\theta, n(\theta))$. Figure 3 plots the withdrawal proportion function $n(\theta)$ and the resulting net incentive $v(\theta)$.

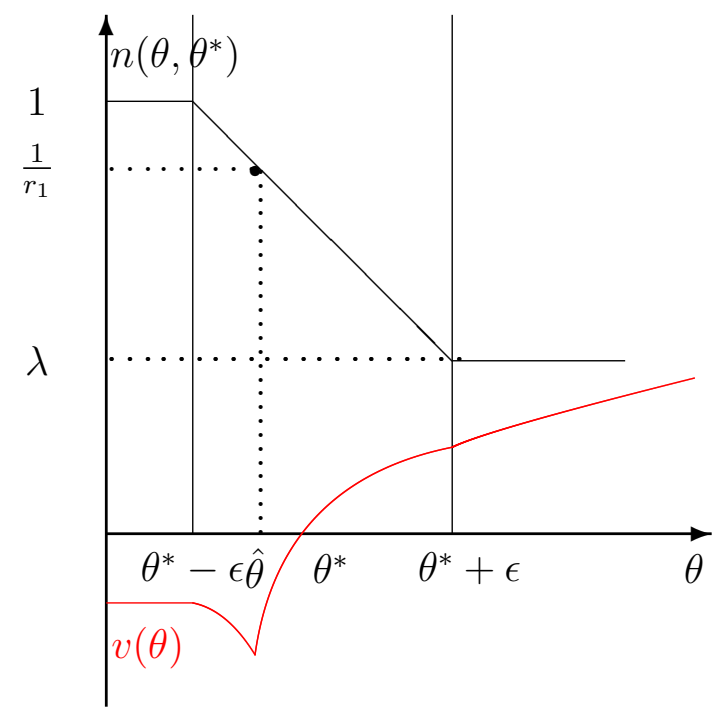

Figure 3: The net incentive $v(\theta)$ and withdrawal proportion $n\left(\theta, \theta^{*}\right)$ for a threshold equilibrium $\theta^{*}$. The level $\hat{\theta}$ is the lowest fundamental for which the bank is solvent.

The posterior induced by the signal $\theta_{i}$ determines the integral of net incentives. It can be written as $\Delta^{r_{1}}\left(\theta_{i}, n().\right)=\frac{1}{2 \epsilon} \int_{\theta_{i}-\epsilon}^{\theta_{i}+\epsilon} v(\theta) d \theta$. It is better to withdraw if and only if the net incentive integral is negative at a signal. The net incentive integral integrates the function $v(\theta)$ in Figure 3 over a rolling window of $\left[\theta_{i}-\epsilon, \theta_{i}+\epsilon\right]$. 
Safe asset holdings complicate the relationship between one-sided strategic complementarity and the uniqueness result. The relevant net incentive term in GP is $p(\theta) u\left(\frac{1-n r_{1}}{1-n} R\right)$. In a threshold equilibrium, an increase in $\theta$ increases $p(\theta)$ and decreases $n(\theta)$. The decrease in $n(\theta)$ mechanically raises the consumption in the good state since $\frac{\partial\left(\frac{1-n r_{1}}{1-n} R\right)}{\partial n}=R \frac{1-r_{1}}{(1-n)^{2}}<0$. The consumption in the bad state is fixed at zero. In contrast, the relevant net incentive term with safe assets, $(1-p(\theta)) u\left(y^{*}\right)+$ $p(\theta) u\left(\frac{1-n r_{1}}{1-n} R-(R-1) y^{*}\right)$, comes from optimal safe asset holdings (Proposition 1$)$. The optimal expected utility of a non-withdrawing investor increases because of the direct effect of $\theta$ itself (Lemma 3) and through the decrease in $n$ (Lemma 1 ). The results are not mechanical and derive from the monotonicity of the optimal expected utility with respect to $\theta$ and $n$ that are formally established in Appendix A.

The proof of Proposition 3 extends the proof of GP to the case of bank portfolio choice and safe assets. It has three steps. First, we show there is a unique symmetric threshold candidate for an equilibrium. Therefore, there exists only one $\theta$ that all patient investors can use as a threshold, where each investor is indifferent between withdrawing and not when receiving this threshold as a signal. That is, the net incentive from withdrawing, $\Delta^{r_{1}}\left(\theta^{\prime}, n\left(., \theta^{\prime}\right)\right)$, is zero at exactly one $\theta^{\prime}$. This rules out the existence of two possible symmetric threshold equilibria. Second, we show that the candidate threshold of step 1 is actually an equilibrium. When all investors except $i$ use the threshold strategies at the $\theta^{\prime}$ computed in step $1, i^{\prime} s$ unique best response is to use a threshold strategy at that $\theta^{\prime}$. Therefore, in steps 1 and 2 , we showed that if we restrict attention to threshold strategies, the identified equilibrium is the unique equilibrium. The third step is to exclude equilibria that are not in threshold strategies.

GP show uniqueness for every positive noise $\epsilon>0$ and assume that the uniqueness of the threshold is conserved as private noise vanishes. However, uniqueness of the threshold $\theta_{\epsilon}^{*}$ at every positive $\epsilon$ does not guarantee convergence to a unique limit. In- 
deed, it may converge to two or many limits. We prove continuity of the threshold with respect to noise. This guarantees a unique limit expressed as $\theta^{*}\left(r_{1}\right) \equiv \lim _{\epsilon \rightarrow 0} \theta_{\epsilon}^{*}\left(r_{1}\right)$. We characterize this limit by the dominated convergence theorem.

Proposition 4. Continuity and vanishing private noise. The withdrawal threshold $\theta_{\epsilon}^{*}$ is continuous in $\epsilon$ for every $\epsilon>0$ and its unique limit $\theta^{*} \equiv \lim _{\epsilon \rightarrow 0} \theta_{\epsilon}^{*}$ is given by

$$
p\left(\theta^{*}\right)=\frac{\frac{u\left(r_{1}\right)}{r_{1}}\left[1-\lambda r_{1}+\ln \left(r_{1}\right)\right]-\int_{\lambda}^{\frac{1}{r_{1}}} u\left(y^{*}\right) d n}{\int_{\lambda}^{\frac{1}{r_{1}}} u\left(\left[\frac{1-n r_{1}}{1-n}-y^{*}\right] R+y^{*}\right) d n-\int_{\lambda}^{\frac{1}{r_{1}}} u\left(y^{*}\right) d n},
$$

where $y^{*}=y^{*}\left(\theta^{*}, n ; r_{1}\right)$ for short. ${ }^{10}$

Proof. See Appendix D.

In the limit of vanishing private noise, $\epsilon \rightarrow 0$, fundamental uncertainty vanishes because investors almost perfectly observe the economic fundamental (and thus the success probability). However, strategic uncertainty - that is, uncertainty about the behavior of other investors - remains in this limit and allows us to determine a unique equilibrium. This result in the limit of the incomplete-information model contrasts with the equilibrium multiplicity in a complete-information benchmark.

The unique limit allows us to classify every fundamental into a full-run region, where $n^{*}=1$ and $\theta<\theta^{*}$, or a no-run region, where $n^{*}=\lambda$ and $\theta \geq \theta^{*}$. The prior about $\theta$ determines the ex-ante probability that the fundamental falls in the full-run region, which is the probability of a bank run. Lemma 2 shows the monotonicity of optimal expected utility in $r_{1}$, which ensures that the threshold $\theta^{*}$ monotonically increases in $r_{1}$ when banks can hold safe assets. Thus, the bank faces a trade-off between higher insurance of investors against their preference shock (higher deposit rate $r_{1}$ ) and heightened probability of a bank run, $\operatorname{Pr}\left\{\theta<\theta^{*}\right\}$. That is, we confirm that this trade-off extends from GP to our environment with portfolio choice.

\footnotetext{
${ }^{10}$ Note that $\theta^{*}$ is defined implicitly because $y^{*}$ also depends on $\theta^{*}$.
} 
Proposition 5. Bank liquidity provision and run probability. A higher deposit rate increases the probability of a run, $\frac{d \theta^{*}}{d r_{1}}>0$.

Proof. See Appendix E.

Using GP as our benchmark, we evaluate the impact of safe asset holdings on the probability of a bank run (for a given deposit rate). Safe asset holdings raise the expected utility of a patient investor when the bank is solvent and have no effect when either the investor is impatient or the bank is insolvent. This increase in expected utility raises the net incentive integral with safe asset holdings, making it positive at GP's threshold. Since this integral increases in the threshold, the threshold has to decrease. Therefore, the withdrawal threshold and the probability of a bank run decrease. Proposition 6 summarizes and Figure 4 illustrates.

Proposition 6. Hedging against investment risk lowers withdrawal incentives. In all subgames, the withdrawal threshold with safe asset holdings is lower,

$$
\theta^{*} \leq \theta_{G P}^{*},
$$

with strict inequality for $r_{1}<\bar{r}_{1}$, where $\bar{r}_{1}$ is the smallest solution to $\theta^{*}\left(\bar{r}_{1}\right)=1$.

Proof. See Appendix F.

\subsection{Deposit rate}

For each subgame given by a deposit rate $r_{1}$, we have calculated the optimal withdrawal decision and safe asset holdings. Integrating over the possible realizations of the fundamental, we calculate the ex-ante expected utility in each subgame. At $t=0$, 


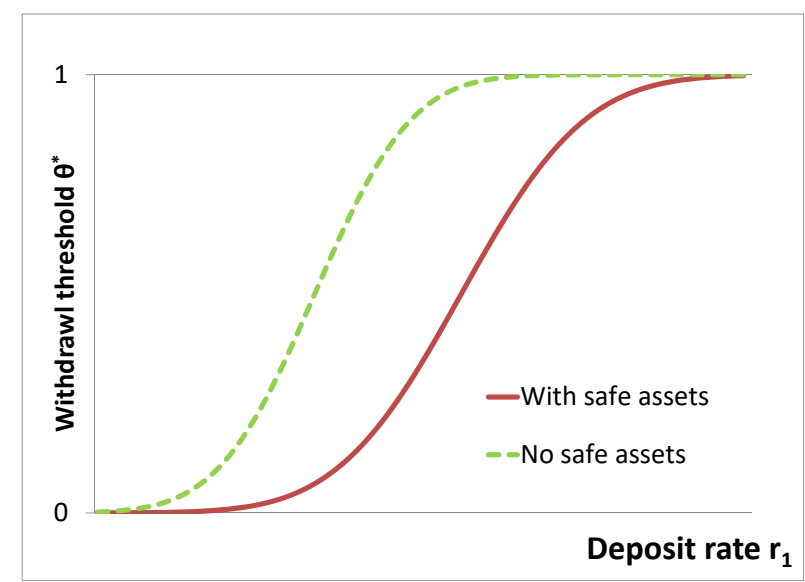

Figure 4: Partial hedging against investment risk via safe asset holdings reduces the withdrawal threshold $\theta^{*}$. The figure shows the withdrawal thresholds with and without safe asset holdings across subgames characterized by a deposit rate $r_{1}$.

the bank chooses the deposit rate $r_{1}$ to maximize ex-ante expected utility:

$$
\begin{array}{rl}
\lim _{\substack{\theta \rightarrow 1 \\
\epsilon \rightarrow 0}} & E U\left(r_{1}\right)=\int_{0}^{\theta^{*}\left(r_{1}\right)} \frac{u\left(r_{1}\right)}{r_{1}} d \theta+\int_{\theta^{*}\left(r_{1}\right)}^{1} \lambda u\left(r_{1}\right)+\cdots \\
& \cdots+(1-\lambda)\left[p(\theta) u\left(\frac{1-\lambda r_{1}}{1-\lambda} R-(R-1) y^{*}\right)+(1-p) u\left(y^{*}\right)\right] d \theta \\
= & \frac{u\left(r_{1}\right)}{r_{1}} \theta^{*}+\lambda\left(1-\theta^{*}\right) u\left(r_{1}\right)+(1-\lambda) \int_{\theta^{*}}^{1} p u\left(\frac{1-\lambda r_{1}}{1-\lambda} R-(R-1) y^{*}\right)+(1-p) u\left(y^{*}\right) d \theta
\end{array}
$$

where $y^{*}=y^{*}\left(\theta, \lambda, r_{1}\right)$ is evaluated at the no-run withdrawal level $n=\lambda$.

Figure 5 shows the ex-ante expected utility for a given deposit rate. The red curve shows the expected utility for each $\theta$. For $\theta<\theta^{*}$, all investors withdraw and each investor receives $r_{1}$ with probability $\frac{1}{r_{1}}$ by sequential service. For $\theta \geq \theta^{*}$, only impatient investors withdraw. An investor's expected utility is a convex combination when impatient, $u\left(r_{1}\right)$, and patient, $p u\left(\frac{1-\lambda r_{1}}{1-\lambda} R-y^{*}(R-1)\right)+(1-p) u\left(y^{*}\right)$ (solid black curves). The red dotted curve shows this convex combination with weight $\lambda$. The ex-ante expected utility integrates over all fundamentals. The figure also indicates the effect of a higher deposit rate, where gray arrows point in the direction of change. 


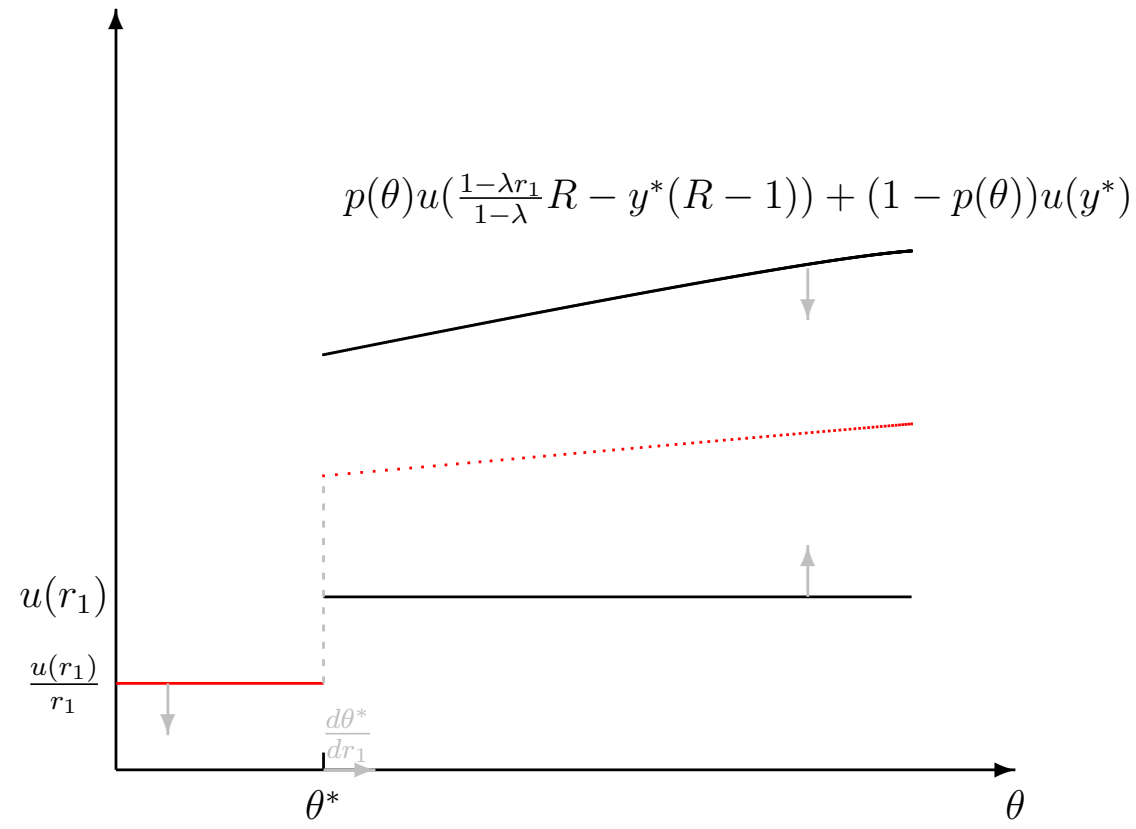

Figure 5: Expected utility for each fundamental $\theta$. For $\theta<\theta^{*}$, a run occurs and the bank is insolvent, so each investor receives $r_{1}$ with probability $\frac{1}{r_{1}}$. For $\theta \geq \theta^{*}$, an investor is impatient with probability $\lambda$, withdraws and receives $r_{1}$. With probability $1-\lambda$, the investor is patient, does not withdraw and consumes safe asset holdings $y^{*}$ or $\frac{1-\lambda r_{1}}{1-\lambda} R-y^{*}(R-1)$. The red curve (dashed above $\theta^{*}$ ) is the $\lambda$-convex combination of the horizontal black line and the upward-sloping black curve. Finally, the gray arrows point to the direction of change as the deposit rate increases.

The optimal deposit rates $r_{1}^{*}$ solves:

$$
\begin{gathered}
\lambda\left(1-\theta^{*}\right) u^{\prime}\left(r_{1}\right)=\frac{u\left(r_{1}\right)-u^{\prime}\left(r_{1}\right) r_{1}}{r_{1}^{2}} \theta^{*}+\lambda R \int_{\theta^{*}}^{1} p(\theta) u^{\prime}\left(\frac{1-\lambda r_{1}}{1-\lambda} R-(R-1) y^{*}\right) d \theta \\
+\frac{d \theta^{*}}{d r_{1}}\left\{\lambda u\left(r_{1}\right)+(1-\lambda)\left[p\left(\theta^{*}\right) u\left(\frac{1-\lambda r_{1}}{1-\lambda} R-(R-1) y^{*}\right)+\left(1-p\left(\theta^{*}\right)\right) u\left(y^{*}\right)\right]-\frac{u\left(r_{1}\right)}{r_{1}}\right\},
\end{gathered}
$$

where the benefit of an increase in the deposit rate $r_{1}$ is better insurance against liquidity shocks (becoming impatient), captured by the left-hand side of equation (8), and represented by the gray arrows pushing $u\left(r_{1}\right)$ up in Figure 5. With probability $\lambda\left(1-\theta^{*}\left(r_{1}\right)\right)$ the investor is impatient and the bank is solvent, resulting in an expected benefit of $\lambda\left(1-\theta^{*}\left(r_{1}\right)\right) u^{\prime}\left(r_{1}\right)$. 
The costs associated with an increase in $r_{1}$ are threefold: lower expected utility in insolvency, loss from additional interim liquidation, and a higher run probability. More precisely, the first cost is a reduced expected utility when the bank is insolvent (with probability $\theta^{*}$ ) because $\frac{u\left(r_{1}\right)}{r_{1}}$ decreases in $r_{1}$. The second cost is the loss suffered by the patient investor when the bank is solvent. An increase in $r_{1}$ means fewer resources for consumption. The third cost is a marginal increase in the insolvency risk, $\frac{d \theta^{*}}{d r_{1}}>0$, where $p\left(\theta^{*}\right) u\left(\frac{1-\lambda r_{1}}{1-\lambda} R-(R-1) y^{*}\right)+\left(1-p\left(\theta^{*}\right)\right) u\left(y^{*}\right)$ is substituted by $\frac{u\left(r_{1}\right)}{r_{1}}$.

Using GP as a benchmark again, the portfolio choice increases both the expected utility in each subgame and investor welfare (the ex-ante expected utility at the optimal deposit rate). There are two channels through which safe asset holdings affect ex-ante expected utility. First, the decrease in the withdrawal threshold creates an interval $\left[\theta^{*}, \theta_{G P}^{*}\right]$. In this interval, ex-ante expected utility increases because states with low expected utility (insolvency) are substituted with states with high expected utility (solvency). Second, when $\theta>\theta_{G P}^{*}$, the expected utility of patient investors is higher. Figure 6 illustrates the impact of safe asset holdings.

Proposition 7 compares the ex-ante expected utility with and without safe asset holdings for a given deposit rate, shown in Figure 7.

Proposition 7. Safe asset holdings increase ex-ante expected utility. In all subgames, the ex-ante expected utility is higher with safe asset holdings than without:

$$
E U\left(r_{1}\right) \geq E U_{G P}\left(r_{1}\right)
$$

with strict inequality in subgames with $r_{1}<\bar{r}_{1}$.

Proof. See Appendix G.

We have shown that the ex-ante expected utility increases in a given subgame 


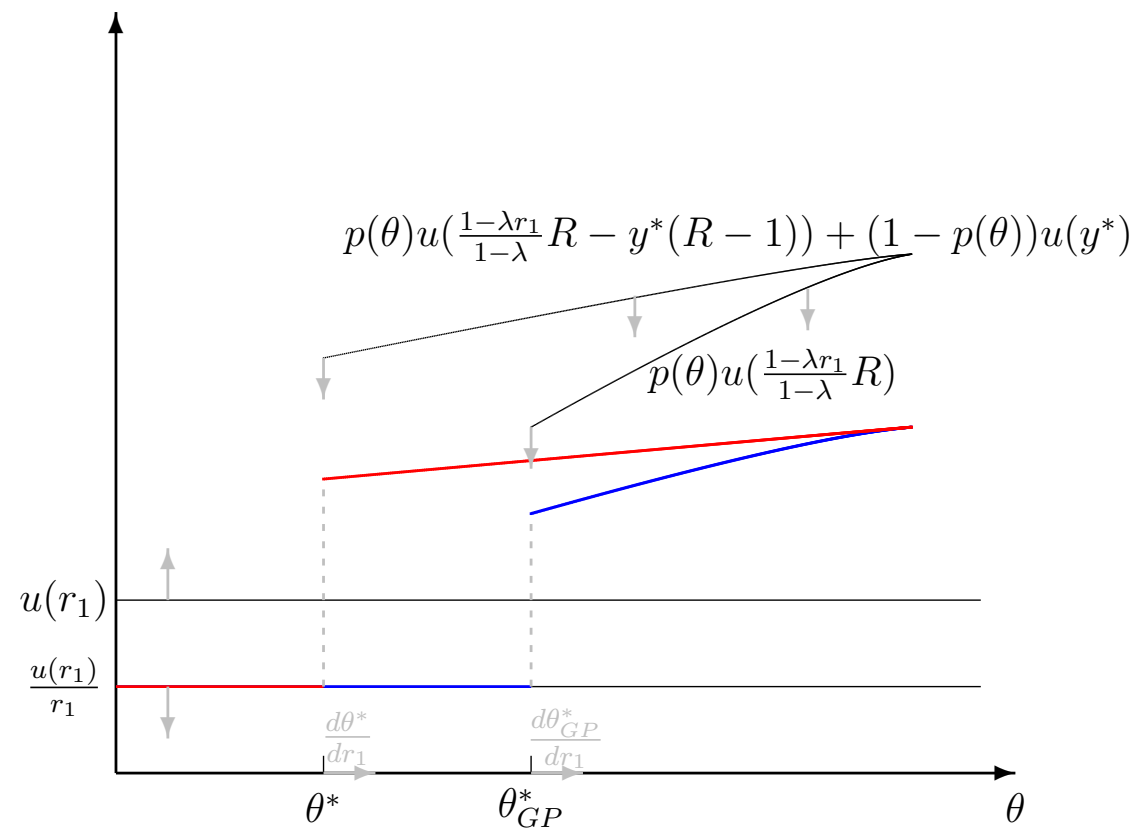

Figure 6: Comparison of expected utility with safe asset holdings (red) and without (blue) in a given subgame. The expected utility with safe asset holdings is unambiguously higher because the run probability is reduced and insurance against investment risk is valuable when the bank is solvent.

when a safe asset becomes available at the interim date. Next, we show that ex-ante expected utility at the respective equilibrium deposit rate is higher with safe asset holdings. The optimum levels of $r_{1}$ with safe asset holdings and without differ, so one needs to compare welfare in each of the resulting equilibria. Let the optimal deposit rates with and without safe asset holdings be $r_{1}^{*}$ and $r_{1, G P}^{*}$, respectively.

Proposition 8. Safe asset holdings increase investor welfare. The expected utility at the optimum deposit rate is higher with safe asset holding:

$$
E U\left(r_{1}^{*}\right)>E U_{G P}\left(r_{1, G P}^{*}\right)
$$




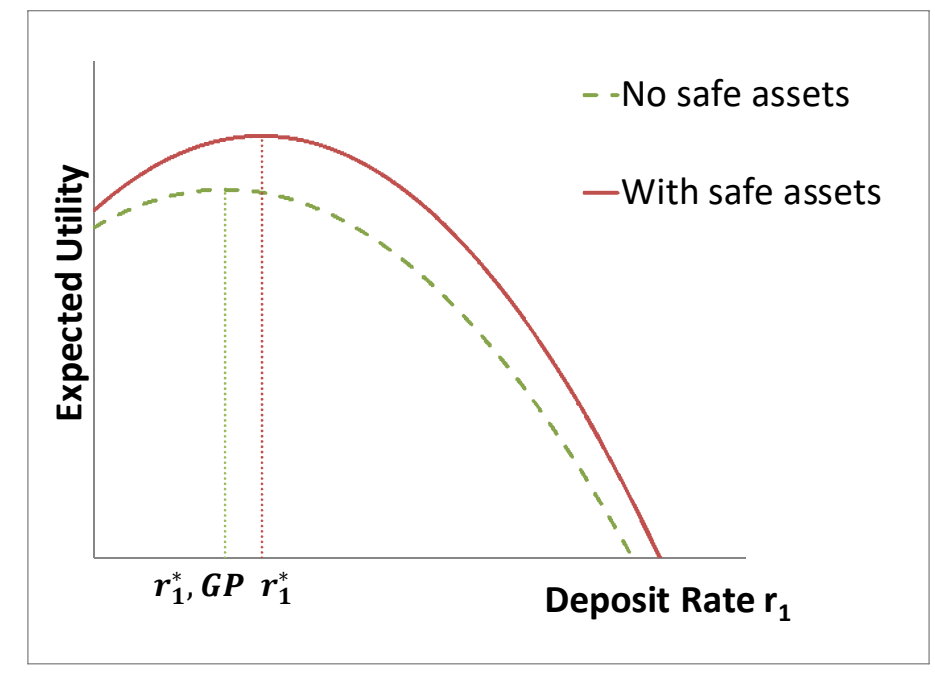

Figure 7: Safe asset holdings increase the ex-ante expected utility in each subgame and result in higher investor welfare and greater bank liquidity provision.

Proof. See Appendix G.

Finally, we analyze the impact of portfolio choice on bank liquidity provision. GP showed that liquidity provision of competitive banks is below its first-best level once the impact of liquidity provision on the endogenous probability of a bank run is considered. We can push this analysis one step further. Since safe asset holdings offer a partial hedge against investment risk and lower the withdrawal incentives of investors, the resulting lower marginal cost of liquidity provision allows competitive banks to offer a higher deposit rate than without safe asset holdings.

Proposition 9. Safe asset holdings increase bank liquidity provision. The deposit rate is higher with safe asset holdings:

$$
r_{1}^{*}>r_{1, G P}^{*}
$$

Proof. See Appendix H. 


\section{Discussion: interim information received by banks}

We have assumed that the bank observes the realized fundamental when choosing its portfolio at the interim date. This assumption may seem crucial, but we show that our main results are robust across alternative information structures. We consider two alternatives. In the first information structure, the bank observes only the withdrawal proportion $n$. Since the bank makes withdrawal payments, it knows the number of investors served. It is thus natural to assume that the bank observes $n$ after all withdrawals occur. ${ }^{11}$ In the second, the bank observes a noisy signal in addition to the withdrawal proportion. A bank typically has no less information than investors about its assets, so the bank's information should be at least as precise.

A change in the information structure has three effects. The first is on the withdrawal threshold, the second is on the ex-ante expected utility, and the third is an indirect effect on expected utility through the withdrawal threshold.

The withdrawal threshold is the same under all three information assumptions, so this effect is void. The withdrawal proportion $n$ aggregates the dispersed private signals of investors. In the interval $\left(\theta^{*}-\epsilon, \theta^{*}+\epsilon\right)$, the withdrawal proportion $n\left(\theta, \theta^{*}\right)$ linearly decreases and is invertible (Figure 8), so it identifies the realized fundamental $\theta$. The net incentive integral at the withdrawal threshold depends only on the utility in this interval. Therefore, the withdrawal threshold remains the only candidate for a unique equilibrium across information structures; that is, $\Delta\left(\theta^{*}, n\left(\cdot, \theta^{*}\right)\right)=0$.

To show that this candidate is an equilibrium, the net incentive integral of $v(\theta)$ on the interval $\left[\theta_{i}-\epsilon, \theta_{i}+\epsilon\right]$ has to be monotone in the signal $\theta_{i}$. The information structure is irrelevant when the bank is insolvent, so the integral is unchanged when

\footnotetext{
${ }^{11}$ Some literature makes assumptions about what the bank observes before and during a run (for example, Ennis and Keister (2009) and references therein). Our assumption, by contrast, is about what the bank observes after a run. That is, we abstract from the bank observing the fundamental and choosing to liquidate investment before withdrawals occur. Such a timing may give rise to signaling by the bank and multiple equilibria (Angeletos et al., 2007).
} 
$\theta_{i}<\theta^{*}$ (see Lemma 7). When $\theta_{i} \geq \theta^{*}$ and the signal increases, the integral increases because negative values of $v(\theta)$ (the red curve at $\theta_{i}-\epsilon$ ) are replaced by positive values of $v(\theta)$ (the blue curve at $\left.\theta_{i}+\epsilon\right) .{ }^{12}$ This proves that the candidate is the unique equilibrium in threshold strategies. Since the one-sided strategic complementarity still holds, this is also the unique equilibrium overall for the three information structures.

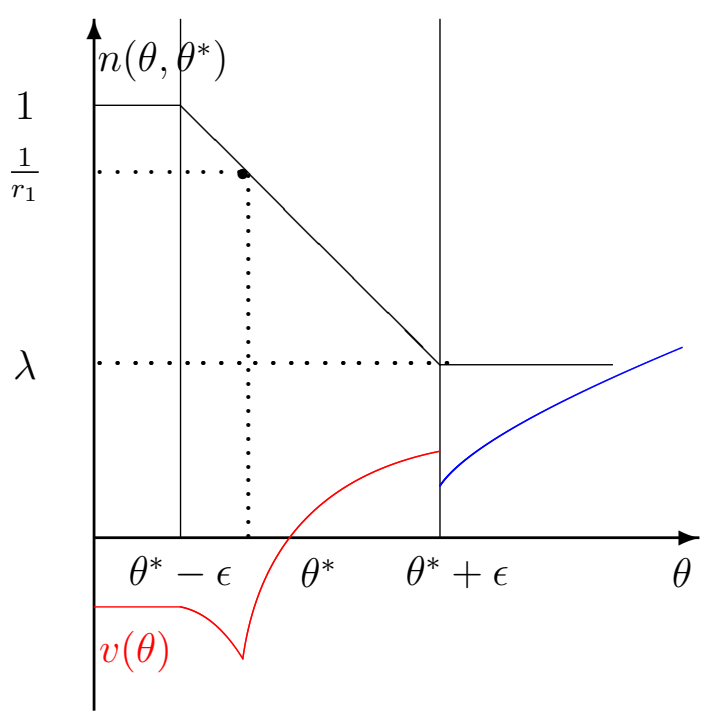

Figure 8: The net incentive $v(\theta)$ when the bank does not observe the fundamental perfectly. We plot the case of $\theta_{i}=\theta^{*}$ and highlight the discontinuity at $\theta^{*}+\epsilon$.

When the bank observes only the withdrawal proportion, it perfectly infers $\theta$ if $n \in(\lambda, 1)$. If the bank observes $n=\lambda$, it has a uniform belief on $\left[\theta^{*}+\epsilon, 1\right]$. The bank chooses optimal safe asset holdings given beliefs, and the differential information may introduce a discontinuity in the expected utility. The expected utility is less than where it would be if the bank perfectly observed the fundamental. When the bank observes $n=\lambda$, the posterior success probability is $E_{\theta}\left[p(\theta) \mid \theta \geq \theta^{*}+\epsilon\right]$ and $v(\theta)$ is the blue curve. This posterior exceeds $p(\theta)$ if $\theta$ is above but close to $\theta^{*}+\epsilon$. This discontinuity notwithstanding, we expect no change in the qualitative results.

\footnotetext{
${ }^{12}$ When the lower bound of integration, $\theta_{i}-\epsilon$, hits $\theta^{*}+\epsilon$, the net integral may decrease. However, it must remain positive (bounded away from zero) because $v(\theta)$ is positive for every $\theta \geq \theta^{*}+\epsilon$.
} 
If the bank observes a noisy signal in addition to $n$, the previous discussion goes through and we obtain the same threshold. The additional signal raises ex-ante expected utility, however, because the bank chooses safe asset holdings in the interval $\left[\theta^{*}+\epsilon, 1\right]$ based on more precise information. As private noise diminishes, expected utility approaches the expected utility for the perfectly observable fundamental case.

\section{Conclusion}

We have studied the portfolio choice of banks in a micro-founded model of runs based on Goldstein and Pauzner (2005). To insure risk-averse investors against liquidity risk, competitive banks offer demand deposits. We use global games to link the portfolio choice to the probability of a bank run. Upon receiving interim information about risky investment, banks liquidate investment to hold a safe asset. This partial hedge against investment risk reduces the withdrawal incentives of investors for a given deposit rate. As a result of the portfolio choice and lower bank fragility for a given deposit rate, banks provide more liquidity ex ante and investor welfare increases.

We have focused on the purely private (unregulated) arrangement and abstracted from incentive problems. An interesting area for future work is to study how the design of guarantees - e.g., along the lines of Allen et al. (2018) - affects the portfolio choice of banks and the implied levels of bank fragility and liquidity provision. In our model, the portfolio choice reduces the expected return of bank assets but increases welfare - the bright side of portfolio choice. In the presence of an incentive problem, lower expected returns would reduce the skin in the game of the banker and thus lower the incentives to exert effort. In such an augmented model, portfolio choice would also have a dark side. We leave these issues for future work. 


\section{References}

Ahnert, T., K. Anand, P. Gai, and J. Chapman (2019). Asset encumbrance, bank funding, and fragility. The Review of Financial Studies 32(6), 2422-55.

Ahnert, T. and A. Kakhbod (2017). Information choice and amplification of financial crises. The Review of Financial Studies 30(6), 2130-178.

Allen, F., E. Carletti, I. Goldstein, and A. Leonello (2018). Government guarantees and financial stability. Journal of Economic Theory 177, 518-57.

Allen, F. and D. Gale (1998). Optimal financial crises. Journal of Finance 53(4), 1245-84.

Allen, F. and D. Gale (2007). Understanding financial crises.

Angeletos, G.-M., C. Hellwig, and A. Pavan (2007). Dynamic global games of regime change: Learning, multiplicity and timing of attacks. Econometrica 75(3), 711-756.

Arrow, K. J. (1963). Liquidity preference. Lecture VI in notes for economics 285, 33-53.

Cooper, R. and T. W. Ross (1998). Bank runs: Liquidity costs and investment distortions. Journal of Monetary Economics 41(1), 27-38.

Cornett, M., J. McNutt, P. Strahan, and H. Tehranian (2011). Liquidity risk management and credit supply in the financial crisis. Journal of Financial Economics 101(2), 297-312.

Diamond, D. and P. Dybvig (1983). Bank runs, deposit insurance and liquidity. Journal of Political Economy 91, 401-419.

Eisenbach, T. M. (2017). Rollover risk as market discipline: A two-sided inefficiency. Journal of Financial Economics 126(2), 252-69.

Ennis, H. and T. Keister (2009). Run equilibria in the green-lin model of financial intermediation. Journal of Economic Theory 144(5), 1996-2020.

Ennis, H. M. and T. Keister (2006). Bank runs and investment decisions revisited. Journal of Monetary Economics 53(2), 217-232. 
Goldstein, I. and A. Pauzner (2005). Demand deposit contracts and the probability of bank runs. Journal of Finance 60(3), 1293-1327.

Liu, X. and A. Mello (2011). The fragile capital structure of hedge funds and the limits to arbitrage. Journal of Financial Economics 102(3), 491-506.

Morris, S., I. Shim, and H. S. Shin (2016). Redemption risk and procyclical cash hoarding by asset managers. Mimeo, Bank for International Settlements.

Morris, S. and H. S. Shin (2000). Rethinking multiple equilibria in macroeconomic modelling. Cowles Foundation Discussion Paper 1260.

Morris, S. and H. S. Shin (2003). Global games: Theory and applications.

Pratt, J. W. (1964). Risk aversion in the small and the large. Econometrica 32, 122-136.

Rochet, J.-C. and X. Vives (2004). Coordination failures and the lender of last resort: was Bagehot right after all? Journal of the European Economic Association 2(6), 1116-1147.

Vives, X. (2014). Strategic complementarity, fragility, and regulation. Review of Financial Studies 27(12), 3547-92.

Zeng, Y. (2016). A dynamic theory of mutual fund runs and liquidity management. Mimeo, University of Washington, St. Louis. 


\section{A Proof of Proposition 1}

The first- and second-order condition with respect to safe asset holdings are

$$
\begin{aligned}
\frac{d U}{d y} & =-p(R-1) u^{\prime}\left(c_{G}\right)+(1-p) u^{\prime}\left(c_{B}\right) \\
\frac{d^{2} U}{d y^{2}} & =-p(R-1)^{2} u^{\prime \prime}\left(c_{G}\right)+(1-p) u^{\prime \prime}\left(c_{B}\right)<0,
\end{aligned}
$$

where $c_{G} \equiv \frac{1-n r_{1}}{1-n} R-y(R-1)$ is consumption in the good state and $c_{B}=y$ is consumption in the bad state. It follows that the objective function is globally concave and the solution to Problem 2, $y^{*}$, is unique.

We turn to corner solutions. First, $y^{*}<\frac{1-n r_{1}}{1-n}$ requires $\left.\frac{d U}{d y}\right|_{y=\frac{1-n r_{1}}{1-n}}<0$, which can be rewritten as $\theta>\underset{\sim}{\theta} \equiv p^{-1}\left(\frac{1}{R}\right)$. Thus, full liquidation occurs for $\theta \leq \underset{\sim}{\theta}$. Second, $y^{*}>0$ requires $\left.\frac{d U}{d y}\right|_{y=0}>0$, which can be rewritten as $u^{\prime}(0)>\frac{p(R-1)}{1-p} u^{\prime}\left(R \frac{1-n r_{1}}{1-n}\right)$. Finally, if the fundamental is in the upper dominance region and investment is no longer risky, then liquidation is dominated, $y^{*}=0$.

We turn to the comparative statics of the optimal interim safe asset holdings. These results follow from the implicit function theorem and the following cross-partial derivatives:

$$
\begin{aligned}
\frac{d^{2} U}{d y d n} & =p R(R-1) \frac{r_{1}-1}{(1-n)^{2}} u^{\prime \prime}\left(c_{G}\right)<0 \\
\frac{d^{2} U}{d y d r_{1}} & =p R(R-1) \frac{n}{1-n} u^{\prime \prime}\left(c_{G}\right)<0 \\
\frac{d^{2} U}{d y d \theta} & =-p^{\prime}(\theta)\left[(R-1) u^{\prime}\left(c_{G}\right)+u^{\prime}\left(c_{B}\right)\right]<0,
\end{aligned}
$$

given our focus on bank liquidity provision, $r_{1}>1$. The partial derivatives of $y^{*}$ follow.

We turn to the three lemmas mentioned in the main text. More withdrawals are detrimental to non-withdrawing investors. For each $\theta$ and $r_{1}$, an increase in $n$ decreases the consumption in the good state, $\frac{\partial}{\partial n}\left(R \frac{1-n r_{1}}{1-n}-y^{*}(R-1)\right)=\frac{1-r_{1}}{(1-n)^{2}}<0$, raising marginal utility. Since the other parts of the first-order condition in equation (3) remain unchanged, the optimal safe asset holdings must decrease to maintain equality, which decreases the 
optimal expected utility. Lemma 1 summarizes.

Lemma 1. Expected utility and withdrawals. For $\underset{\sim}{\theta}<\theta<\bar{\theta}$ and a solvent bank, consumption and optimal expected utility of non-withdrawing investors decrease in $n$.

Proof. Let $\underset{\sim}{\theta}<\theta<\bar{\theta}$. When the bank is solvent $\lambda \leq n<\frac{1}{r_{1}}$, we get an interior solution for safe asset holdings $y^{*}\left(\theta, n, r_{1}\right)$. Let $n^{\prime}>n, y^{\prime}$ and $y$ be the optimal interior safe asset holdings that solve the respective problems in 2. Using equation (3) yields

$$
\frac{u^{\prime}(y)}{u^{\prime}\left(\frac{1-n r_{1}}{1-n} R-y(R-1)\right)}=\frac{p(R-1)}{1-p}=\frac{u^{\prime}\left(y^{\prime}\right)}{u^{\prime}\left(\frac{1-n^{\prime} r_{1}}{1-n^{\prime}} R-y^{\prime}(R-1)\right)}
$$

First, assume $y^{\prime}=y$. By strict concavity of $u(c)$, we get $\frac{1-n r_{1}}{1-n}=\frac{1-n^{\prime} r_{1}}{1-n^{\prime}}$. This implies $n=n^{\prime}$ because $\frac{1-n r_{1}}{1-n}$ decreases in $n$ when $r_{1}>1$, a contradiction. Thus, $y^{\prime} \neq y$. Second, assume $y^{\prime}>y$. By strict concavity, we have $u^{\prime}\left(y^{\prime}\right)<u^{\prime}(y)$. By equation (17) and strict concavity, we get $\frac{1-n^{\prime} r_{1}}{1-n^{\prime}} R-y^{\prime}(R-1)>\frac{1-n r_{1}}{1-n} R-y(R-1)$ and $\left(y-y^{\prime}\right) \frac{(R-1)}{R}>\frac{1-n r_{1}}{1-n}-\frac{1-n^{\prime} r_{1}}{1-n^{\prime}}$. Since $y-y^{\prime}<0, \frac{1-n^{\prime} r_{1}}{1-n^{\prime}}>\frac{1-n r_{1}}{1-n}$, which implies $n^{\prime}<n$, another contradiction. Taken together, we have shown that $y^{\prime}<y$ and the consumption level in the bad state decreases in $n$. Finally, $y^{\prime}<y$ implies $u^{\prime}\left(y^{\prime}\right)>u^{\prime}(y)$. Equation (17) and strict concavity imply that $\frac{1-n^{\prime} r_{1}}{1-n^{\prime}} R-y^{\prime}(R-1)<\frac{1-n r_{1}}{1-n} R-y(R-1)$. Thus, the consumption level in the good state also decreases in $n$. Since the consumption in both states decreases in $n$, so does the expected utility of the non-withdrawing investor.

Consider a solvent bank for a fixed $\theta$. A higher deposit rate $r_{1}$ decreases marginal utility in the good state and reduces optimal expected utility. The effect is similar to that in Lemma 1 and summarized in Lemma 2.

Lemma 2. Expected utility and deposit rate. Let $\underset{\sim}{\theta}<\theta<\bar{\theta}$. For a solvent bank, consumption in both states decreases in $r_{1}$, so the optimal expected utility of a non-withdrawing investor decreases in $r_{1}$.

Proof. Let $\underset{\sim}{\theta}<\theta<\bar{\theta}$. When the bank is solvent $\lambda \leq n<\frac{1}{r_{1}}$, we get an interior solution for $y^{*}\left(\theta, n, r_{1}\right)$. Let $r_{1}^{\prime}>r_{1}, y^{\prime}$ and $y$ be the optimal interior safe asset holdings that solve 
the respective problems in 2. Using equation (3) yields

$$
\frac{u^{\prime}(y)}{u^{\prime}\left(\frac{1-n r_{1}}{1-n} R-y(R-1)\right)}=\frac{p(R-1)}{1-p}=\frac{u^{\prime}\left(y^{\prime}\right)}{u^{\prime}\left(\frac{1-n r_{1}^{\prime}}{1-n} R-y^{\prime}(R-1)\right)}
$$

Assume $y^{\prime}=y$. This implies $\frac{1-n r_{1}}{1-n}=\frac{1-n r_{1}^{\prime}}{1-n}$ and $r_{1}=r_{1}^{\prime}$, a contradiction. Next, assume $y^{\prime}>y$. Steps similar to the proof of Lemma 1 lead to the required contradiction.

Consider a solvent bank for a fixed $r_{1}$. At an interior safe asset holding, the optimal expected utility increases and is continuous in $\theta$. Consumption is higher in the good state, $\frac{1-n r_{1}}{1-n} R-y^{*}(R-1)>y^{*}$, and expected utility is a convex combination of utility in both states, $p(\theta) u\left(R\left[\frac{1-n r_{1}}{1-n}\right]-(R-1) y^{*}\right)+(1-p(\theta)) u\left(y^{*}\right)$. Hence, an increase in the weight on the good state, $\theta$, without adjusting safe assets, raises expected utility. Allowing safe assets to adjust increases expected utility further. Taken together, we have the following result.

Lemma 3. Expected utility and fundamental. Let $\underset{\sim}{\theta}<\theta<\bar{\theta}$. For a solvent bank, the optimal expected utility of a non-withdrawing investor is continuous and increases in $\theta$. (For an insolvent bank, it is independent of $\theta$.)

Proof. Let $\underset{\sim}{\theta}<\theta<\bar{\theta}$. For a solvent bank, the solution is determined by equation (3). The continuity of $y^{*}$ in $\theta$ follows from the continuity of marginal utility, $u^{\prime}(\cdot)$, and of the success probability, $p(\cdot)$. The continuity of optimal expected utility follows. To prove that the optimal expected utility increases in $\theta$, let $p^{\prime}>p$ be short for $\theta^{\prime}>\theta$ and the respective optimal safe asset holdings be $y^{\prime}$ and $y$. Optimality of $y^{\prime}$ and strict concavity imply

$$
p^{\prime} u\left(\frac{1-n r_{1}}{1-n} R-y^{\prime}(R-1)\right)+\left(1-p^{\prime}\right) u\left(y^{\prime}\right)>p^{\prime} u\left(\frac{1-n r_{1}}{1-n} R-y(R-1)\right)+\left(1-p^{\prime}\right) u(y) .
$$

Since $y$ is interior, we have $y<\frac{1-n r_{1}}{1-n}$ and thus both $y<\frac{1-n r_{1}}{1-n} R-y(R-1)$ and $u(y)<$ $u\left(\frac{1-n r_{1}}{1-n} R-y(R-1)\right) . p^{\prime}>p$ implies $p^{\prime} u\left(c_{G}\right)+\left(1-p^{\prime}\right) u(y)>p u\left(c_{G}\right)+(1-p) u(y)$. Combining both inequalities yields strict monotonicity. 


\section{B Proof of Proposition 2}

Consider a fixed $r_{1} \in\left(1, \frac{R}{1+\lambda(R-1)}\right)$. For an insolvent bank, withdrawing at $t=1$ yields expected utility $\frac{u\left(r_{1}\right)}{n r_{1}}$ and waiting yields $u(0)=0$, so a patient investor prefers to withdraw. Consider a solvent bank next. To use the intermediate value theorem, we show that the expected utility differential is negative at $\theta=0$ and positive on the upper dominance region. Fix $n=\lambda$. At $\theta=0$, the investment certainly fails because $p(0)=0$. Therefore, all investment is liquidated, $y^{*}=\frac{1-\lambda r_{1}}{1-\lambda}$. Thus, a non-withdrawing patient investor's expected utility at the interim date is $u\left(\frac{1-\lambda r_{1}}{1-\lambda}\right)$, which is below $u\left(r_{1}\right)$ because $r_{1}>1$, the lower bound on $r_{1}$. When $\theta \geq \bar{\theta}$, the investment certainly succeeds, $p(\theta)=1$. Insurance against investment risk is zero, $y^{*}=0$, and all resources remain invested. The interim-date expected utility is $u\left(\frac{1-\lambda r_{1}}{1-\lambda} R\right)>u\left(r_{1}\right)$ because $r_{1}<\frac{R}{1+\lambda(R-1)}$, the upper bound on $r_{1}$.

For each $r_{1}$, by the continuity of expected utility in $\theta$ at $n=\lambda$ (Lemma 3), there is a cut-off $\underline{\theta}\left(r_{1}\right)$ defined by $p\left(\underline{\theta}\left(r_{1}\right)\right) u\left[\frac{1-\lambda r_{1}}{1-\lambda} R-y^{*}(R-1)\right]+\left(1-p\left(\underline{\theta}\left(r_{1}\right)\right)\right) u\left(y^{*}\right)=u\left(r_{1}\right)$ by the intermediate value theorem. Since the expected utility increases in $\theta$ when $n=\lambda$ by Lemma 3 , we have $p(\theta) u\left[\frac{1-\lambda r_{1}}{1-\lambda} R-y^{*}(R-1)\right]+(1-p(\theta)) u\left(y^{*}\right)<u\left(r_{1}\right)$ for any $\theta<\underline{\theta}\left(r_{1}\right)$.

Because the optimal expected utility at the interim date decreases in $n$ at every $\theta<\underline{\theta}$, Lemma 1 shows that for all $n>\lambda$, the patient investor still has a dominant strategy to withdraw at $t=1$. This establishes a lower dominance region for every $r_{1}$ in the domain.

Let $r_{1}^{\prime}>r_{1}$, and $y^{\prime}, y$ solve the respective problems in 2 with associated bounds $\underline{\theta}^{\prime}$ and $\underline{\theta}$. Note that $p(\underline{\theta}) u\left[\frac{1-\lambda r_{1}}{1-\lambda} R-y(R-1)\right]+(1-p(\underline{\theta})) u(y)=u\left(r_{1}\right)$. When $r_{1}$ increases to $r_{1}^{\prime}$, the expected utility evaluated at $p(\underline{\theta})$ decreases by Lemma 2. But to raise the expected utility to $u\left(r_{1}^{\prime}\right)>u\left(r_{1}\right), \underline{\theta}$ must increase by Lemma 3. This establishes strict monotonicity of $\underline{\theta}\left(r_{1}\right)$ in $r_{1}$. The discussion at the beginning shows that $\underline{\theta} \rightarrow 1$ when $r_{1} \rightarrow \frac{R}{1+\lambda(R-1)}$. 


\section{Proof of Proposition 3}

The proof that the symmetric threshold equilibrium is unique is in four steps. In step C.1, we show that there is a unique threshold $\theta^{\prime}$ : if all investors except $i$ use $\theta^{\prime}$ as a threshold strategy, then $i$ would be exactly indifferent between withdrawing and not when upon receiving the signal $\theta_{i}=\theta^{\prime}$. In step C.2, we show that $\theta^{\prime}$ is actually a symmetric threshold equilibrium: $i$ withdraws when his signal is below the threshold $\theta_{i}<\theta^{\prime}$ and does not when above it $\theta_{i}>\theta^{\prime}$. Steps C.1 and C.2 prove that there is a unique equilibrium when we restrict strategies to be symmetric threshold strategies. Step C.3 extends the equilibrium uniqueness to all threshold strategies. Step C.4 shows that no equilibrium different from a symmetric threshold equilibrium can exist. These four steps prove uniqueness in all strategies.

\section{C.1 Unique threshold candidate}

A threshold strategy for investor $i$ is a function that maps deposit rates $r_{1}$ into a threshold signal $\theta_{i}^{\prime}$, whereby $i$ (does not) withdraws when the signal is below (above) the threshold.

The first step of the proof shows a unique candidate for a symmetric threshold equilibrium, ruling out multiple symmetric threshold equilibria. Fix a subgame defined by an deposit rate $r_{1}$ and assume all investors except $i$ use the same threshold strategy at a $\theta^{\prime}=\theta^{\prime}\left(r_{1}\right)$. By the law of large numbers, investor $i^{\prime} s$ belief about the proportion of investors who withdraw at a realized fundamental $\theta, n\left(\theta, \theta^{\prime}\right)$, is degenerate and defined by

$$
n\left(\theta, \theta^{\prime}\right)= \begin{cases}1 & \text { if } \theta \leq \theta^{\prime}-\epsilon \\ \lambda+(1-\lambda)\left(\frac{1}{2}+\frac{\theta^{\prime}-\theta}{2 \epsilon}\right) & \text { if } \theta^{\prime}-\epsilon \leq \theta \leq \theta^{\prime}+\epsilon \\ \lambda & \text { if } \theta \geq \theta^{\prime}+\epsilon\end{cases}
$$

Writing $y^{*}$ as a shorthand for $y^{*}\left(\theta, n, r_{1}\right)$, $i$ 's net incentive at any $\theta$ and $n$ is

$$
v\left(\theta, n ; r_{1}\right)= \begin{cases}(1-p(\theta)) u\left(y^{*}\right)+p u\left(\left(\frac{1-n r_{1}}{1-n}-y^{*}\right) R+y^{*}\right)-u\left(r_{1}\right) & \text { if } \lambda \leq n \leq \frac{1}{r_{1}} \\ -\frac{1}{n r_{1}} u\left(r_{1}\right) & \text { if } \frac{1}{r_{1}} \leq n \leq 1\end{cases}
$$


The proposed threshold strategies pin down the proportion of withdrawals as a function of the realized fundamental: $n\left(\theta, \theta^{\prime}\right)$. This allows us to compute $i$ 's net incentive at a realized fundamental $\theta$ as $v(\theta)=v\left(\theta, n\left(\theta, \theta^{\prime}\right)\right)$. Investor $i$ does not observe the realized fundamental $\theta$, however, only a signal $\theta_{i}$. At signal $\theta_{i}$, his posterior on $\theta$ is uniform over the interval $\left[\theta_{i}-\epsilon, \theta_{i}+\epsilon\right]$. Therefore, $i$ 's net expected utility of not withdrawing versus withdrawing at signal $\theta_{i}$ is represented by the integral of net incentives: $\Delta^{r_{1}}\left(\theta_{i}, n\left(., \theta^{\prime}\right)\right)=\frac{1}{2 \epsilon} \int_{\theta_{i}-\epsilon}^{\theta_{i}+\epsilon} v(\theta) d \theta$.

We will show that $i$ 's integral of net incentives when he receives the threshold $\theta^{\prime}$ as a signal: $\Delta^{r_{1}}\left(\theta^{\prime}, n\left(., \theta^{\prime}\right)\right)$ intersects zero at exactly one point $\theta^{\prime}$, which we call $\theta^{*}$. It is negative below it $\left(\Delta^{r_{1}}\left(\theta^{\prime}, n\left(., \theta^{\prime}\right)\right)<0\right.$ when $\left.\theta^{\prime}<\theta^{*}\right)$ and positive above it $\left(\Delta^{r_{1}}\left(\theta^{\prime}, n\left(., \theta^{\prime}\right)\right)>0\right.$ when $\left.\theta^{\prime}>\theta^{*}\right)$. Hence, $\theta^{*}$ is the unique potential threshold for a symmetric threshold equilibrium.

We prove the uniqueness of $\theta^{*}$ by the intermediate value theorem. The argument is complicated by the fact that when $\theta^{\prime}$ is close to the upper dominance region: $\bar{\theta}-\epsilon \leq \theta^{\prime} \leq$ $\bar{\theta}+\epsilon$, the function $v(\theta)$ is not monotone in $\theta$ over $\left[\hat{\theta}, \theta^{\prime}+\epsilon\right]$, where $\hat{\theta}$ is defined below. $v(\theta)$ might increase at first, then discontinuously jumps at $\bar{\theta}$ and decreases. We show that this decrease preserves the single crossing of the integral of net incentives and the uniqueness of $\theta^{*}$. We analyze $v(\theta)$ in two cases: case $\mathrm{I}$ is when the threshold $\theta^{\prime}$ is far from the upper dominance region $\left(\theta^{\prime} \leq \bar{\theta}-\epsilon\right)$, while case II is when it is closer to it $\left(\bar{\theta}-\epsilon \leq \theta^{\prime} \leq \bar{\theta}+\epsilon\right){ }^{13}$

Case I: $\theta^{\prime} \leq \bar{\theta}-\epsilon . \quad v(\theta)$ achieves its minimum at $\hat{\theta} \in\left(\theta^{\prime}-\epsilon, \theta^{\prime}+\epsilon\right)$, where the proportion of investors withdrawing is equal to $\frac{1}{r_{1}} \cdot{ }^{14}$ As $\theta$ increases from $\theta^{\prime}-\epsilon$ to $\hat{\theta}, n$ decreases from 1 to $\frac{1}{r_{1}}$ and $v(\theta)=-\frac{u\left(r_{1}\right)}{n r_{1}}$ decreases to its minimum value $-u\left(r_{1}\right)$. On the interval $\left[\hat{\theta}, \theta^{\prime}+\epsilon\right]$, $v(\theta)=(1-p(\theta)) u\left(y^{*}\right)+p(\theta) u\left(\left(\frac{1-n r_{1}}{1-n}-y^{*}\right) R+y^{*}\right)-u\left(r_{1}\right)$. As $\theta$ increases from $\hat{\theta}$ to $\theta^{\prime}+\epsilon, n$ decreases from $\frac{1}{r_{1}}$ to $\lambda$. The increase in $\theta$ coupled with the decrease in $n\left(\theta, \theta^{\prime}\right)$ means that the combination of Lemma 1 and Lemma 3 insure $v(\theta)$ increases in $\theta$. At $\bar{\theta}$, the liquidation value discontinuously increases from 1 to $R$, which results in a discontinuous $v(\theta)$. By the

\footnotetext{
${ }^{13} \mathrm{We}$ analyze the net incentive integral to compute $i$ 's best response to symmetric threshold strategies. Investors with signals $\theta_{i} \geq \bar{\theta}+\epsilon$ are sure that $\theta$ is in the upper dominance region. Irrespective of $n$, withdrawing in the region $\left[\bar{\theta}+\epsilon, \theta^{\prime}\right]$ is a strictly dominated strategy. Although we can still analyze when the threshold $\theta^{\prime}$ exceeds $\bar{\theta}+\epsilon$, but this case adds little and we drop it.

${ }^{14}$ Over the segment $\left\{\theta: \lambda \leq n\left(\theta, \theta^{\prime}\right) \leq 1\right\}, n\left(., \theta^{\prime}\right)$ is linearly decreasing and hence invertible. Therefore, let $\hat{\theta} \equiv \theta: n\left(\theta, \theta^{\prime}\right)=\frac{1}{r_{1}}$. By the intermediate value theorem $\hat{\theta}$ exists, and $\theta^{\prime}-\epsilon<\hat{\theta}<\theta^{\prime}+\epsilon$.
} 
continuity of $p($.$) and because p(\bar{\theta})=1, v(\theta)$ approaches $u\left(\frac{1-\lambda r_{1}}{1-\lambda} R\right)-u\left(r_{1}\right)$ as $\theta$ approaches $\bar{\theta}$. But $v(\theta)=u\left(\frac{\mathbf{R}-\lambda r_{1}}{1-\lambda} R\right)-u\left(r_{1}\right)$ for all $\theta \geq \bar{\theta}$. Figure 9 shows the discussion.

As $\theta^{\prime}$ changes, the interval $\left[\theta^{\prime}-\epsilon, \hat{\theta}\right]$ remains of constant length. Using $n\left(\hat{\theta}, \theta^{\prime}\right)=\frac{1}{r_{1}}$, we see that $\theta^{\prime}-\hat{\theta}=\left(\frac{1}{r_{1}}-\frac{1+\lambda}{2}\right) \frac{2 \epsilon}{1-\lambda}$, which is independent of $\theta^{\prime}$. On $\left[\theta^{\prime}-\epsilon, \hat{\theta}\right], v(\theta)$ depends on $\theta^{\prime}$ only through $n, v(\theta)=-\frac{u\left(r_{1}\right)}{n r_{1}}$. Therefore, $v(\theta)$ on this interval is merely translated sideways as $\theta^{\prime}$ changes, and the integral $\int_{\theta^{\prime}-\epsilon}^{\hat{\theta}} v(\theta) d \theta$ remains constant. As $\theta^{\prime}$ increases, $v(\theta)$ is evaluated at a translation to the right of the interval $\left[\hat{\theta}, \theta^{\prime}+\epsilon\right]$. Therefore, at a fixed $n$ but higher fundamental, $v(\theta)$ increases by Lemma 3. Figure 10 plots $v(\theta)$ at two different thresholds $\theta_{1}^{\prime}<\theta_{2}^{\prime}$. The blue plot of $v(\theta)$ on interval $\left[\hat{\theta}, \theta_{2}^{\prime}+\epsilon\right]$ is clearly higher than the black plot on interval $\left[\hat{\theta}, \theta_{1}^{\prime}+\epsilon\right]$. Clearly, $\int_{\hat{\theta}}^{\theta^{\prime}+\epsilon} v(\theta) d \theta$ increases in the threshold $\theta^{\prime}$.

Case II: $\bar{\theta}-\epsilon<\theta^{\prime} \leq \bar{\theta}+\epsilon$. The graph of $v(\theta)$ is similar to case I on the interval $\left[\theta^{\prime}-\epsilon, \bar{\theta}\right)$, with a minor difference regarding $\hat{\theta}$. If $\hat{\theta}<\bar{\theta}$, then $v(\theta)$ decreases first, achieves its minimum at $\hat{\theta}$, then increases and exhibits a point of discontinuity at $\bar{\theta}$. When $\hat{\theta} \geq \bar{\theta}$, however, $v(\theta)$ decreases and approaches an infimum value at $\bar{\theta}$ but never achieves it and exhibits a point of discontinuity at $\bar{\theta}$. In both cases, for $\theta \in\left[\bar{\theta}, \theta^{\prime}+\epsilon\right], v(\theta)$ has the peculiar feature that it decreases in $\theta$. On this interval, $v(\theta)=u\left(\frac{R-n r_{1}}{1-n} R\right)-u\left(r_{1}\right)$, which increases in $n$. This presents a reversal in the incentives: an increase in $n$ is good news to those who do not withdraw. Since the project is riskless now, an increase in $\theta$ mainly implies an increase in $n$. Therefore, on $\theta \in\left[\bar{\theta}, \theta^{\prime}+\epsilon\right], v(\theta)$ decreases in $\theta$, until it becomes constant at $u\left(\frac{R-\lambda r_{1}}{1-\lambda} R\right)-u\left(r_{1}\right)$, when $\theta$ is above $\theta^{\prime}+\epsilon$. Figure 11 plots a representative $v(\theta)$.

Two issues are important to show that the Case II integral of net incentives increases in $\theta^{\prime}$. First is the change in $v(\theta)$ as $\theta^{\prime}$ increases. At $\theta^{\prime}=\bar{\theta}-\epsilon, v(\theta)$ would be almost identical to Figure 9. As $\theta^{\prime}$ increases, the interval $\left[\theta^{\prime}-\epsilon, \bar{\theta}\right]$ shrinks and $v(\theta)$ would resemble Figure 9 on the domain below $\bar{\theta}$, and Figure 11 on the domain above $\bar{\theta}$. Second, we show that $u\left(\frac{R-n r_{1}}{1-n} R\right)-u\left(r_{1}\right) \geq u\left(\frac{R-\lambda r_{1}}{1-\lambda} R\right)-u\left(r_{1}\right)>0$. The first inequality is discussed before, while the second is evident. (This expression is positive because $\frac{R-n r_{1}}{1-n}$ increases in $n$ as $r_{1}<R$ and $\frac{R-\lambda r_{1}}{1-\lambda}>r_{1}$. As $\theta^{\prime}$ increases, the integral increases because positive values of $v(\theta)$ are added and negative ones are dropped. This discussion proves the following result: 


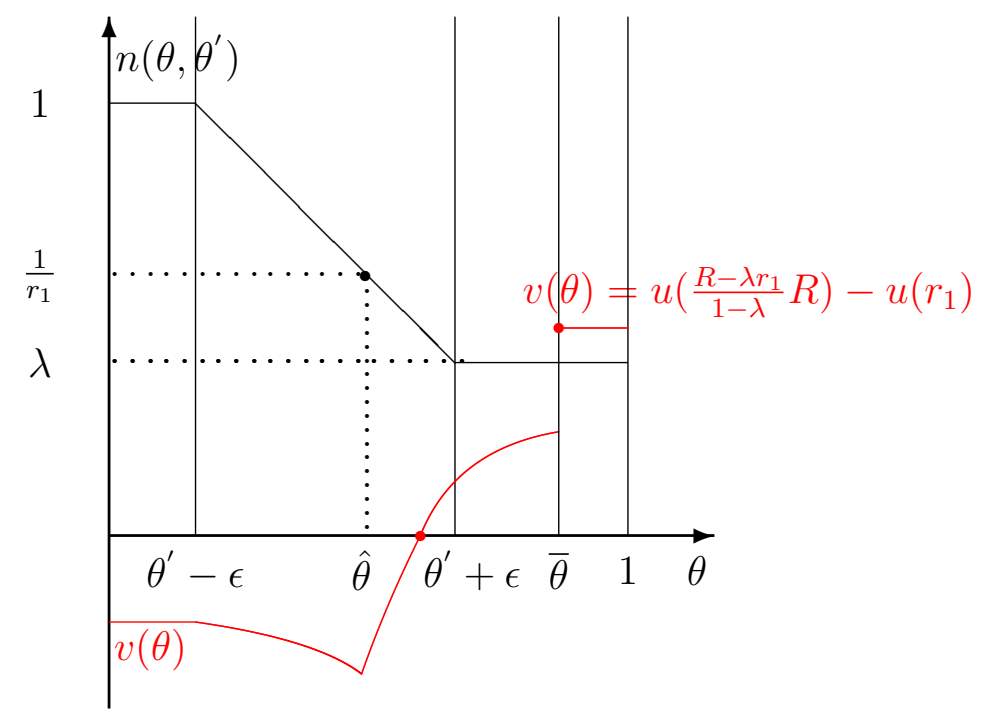

Figure 9: Net incentives when the threshold is far below the upper dominance region, $\theta^{\prime}+\epsilon \leq \bar{\theta}$.

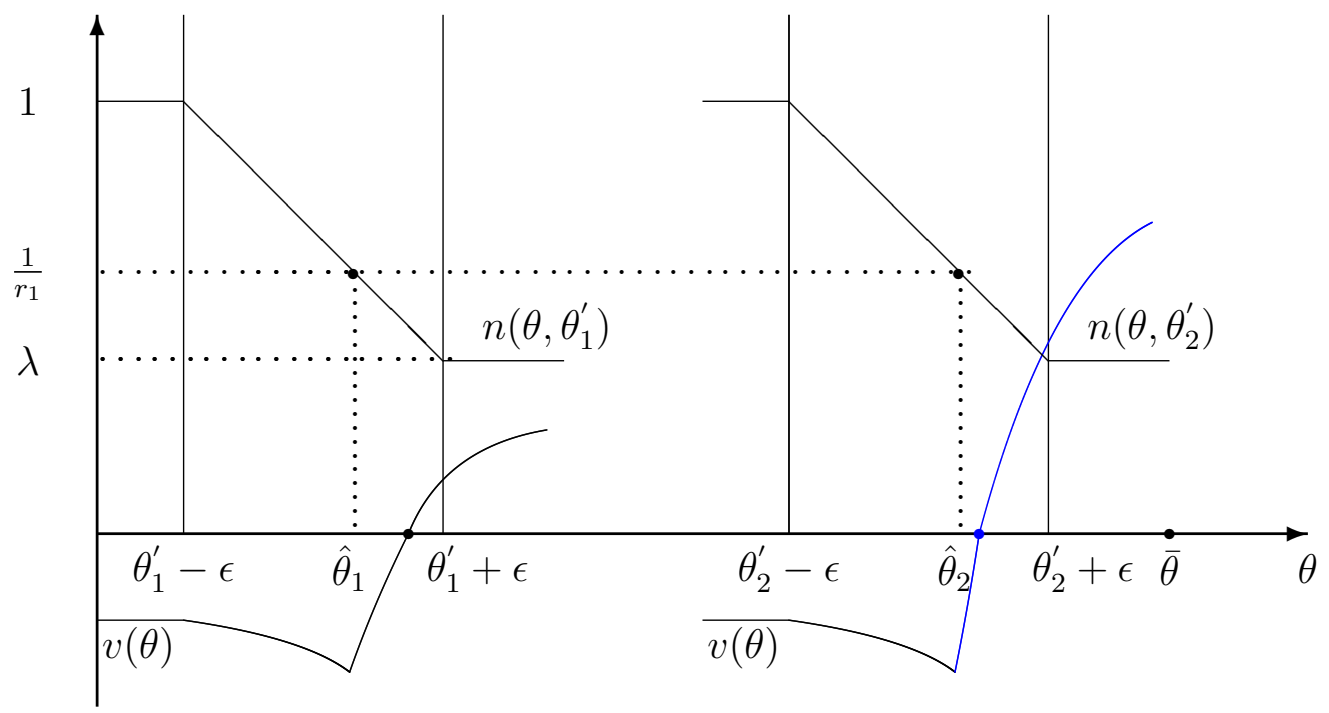

Figure 10: The net incentive with two thresholds $\left(\theta_{2}^{\prime}>\theta_{1}^{\prime}\right)$. The curves representing $v(\theta)$ on $\left[\theta_{1}^{\prime}-\epsilon, \hat{\theta}_{1}\right]$ and $\left[\theta_{2}^{\prime}-\epsilon, \hat{\theta}_{2}\right]$ are identical. The increasing black curve on $\left[\hat{\theta}_{1}, \theta_{1}^{\prime}+\epsilon\right]$ is lower than the increasing blue curve on $\left[\hat{\theta}_{2}, \theta_{2}^{\prime}+\epsilon\right]$. This depicts an integral of net incentives $\int_{\hat{\theta}}^{\theta^{\prime}+\epsilon} v(\theta) d \theta$ that increases in the threshold $\theta^{\prime}$. 


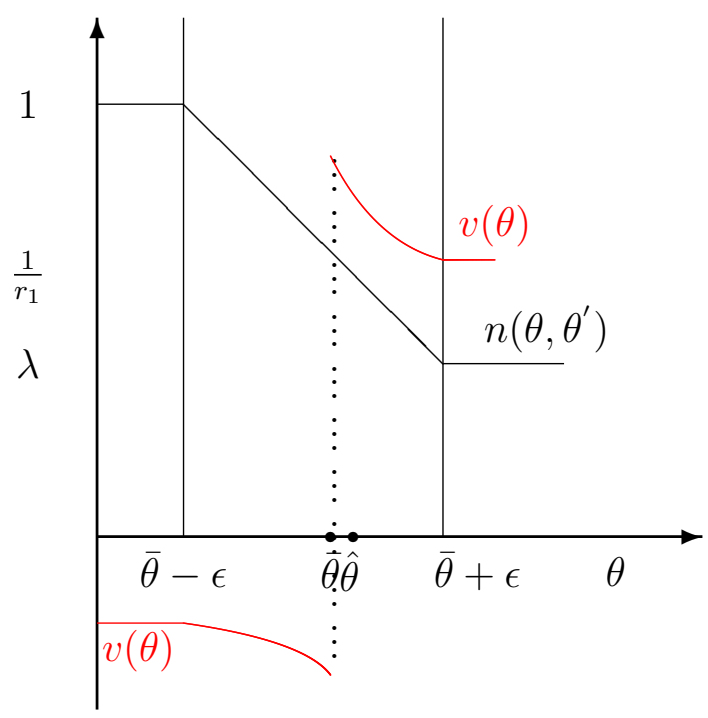

Figure 11: Net incentives for $\theta^{\prime}=\bar{\theta}$ and $\hat{\theta}>\bar{\theta}$.

Lemma 4. There exists an $\epsilon$ such that $\Delta^{r_{1}}\left(\theta^{\prime}, n\left(., \theta^{\prime}\right)\right)$ increases in $\theta^{\prime}$.

To show the existence and uniqueness of $\theta^{*}$, the following lemma proves that $\Delta^{r_{1}}\left(\theta^{\prime}, n\left(., \theta^{\prime}\right)\right)$ is continuous in $\theta^{\prime}$. Next we show that it starts negative when $\theta^{\prime}$ is close to 0 and increases until it is positive. The intermediate value theorem and strict monotonicity then prove the claim.

Lemma 5. The integral $\Delta^{r_{1}}\left(\theta^{\prime}, n\left(., \theta^{\prime}\right)\right)$ is continuous in $\theta^{\prime}$.

Proof. The integrand is bounded, which makes the continuity of the integral straightforward. Because the discontinuity in $v(\theta)$ is a simple discontinuity, it has no effect on the continuity of the integral.

That the integral is positive on the higher part of the upper dominance region when $\epsilon$ is small enough is clear by the discussion when $\theta^{\prime}$ goes to $\hat{\theta}+\epsilon$. Next we show it is negative, when $\theta^{\prime}$ is close to zero. For the lower dominance region, fix $r_{1}>1$, we have that $\underline{\theta}\left(r_{1}\right)>0$. Hence, there exists a $\bar{\epsilon}\left(r_{1}\right)>0$ small enough, such that $\underline{\theta}\left(r_{1}\right)-3 \bar{\epsilon}\left(r_{1}\right)>0$. When 
$\theta^{\prime}<\underline{\theta}\left(r_{1}\right)-\epsilon\left(r_{1}\right)$, we have $v(\theta)<0$ for all $\theta \in\left[\theta^{\prime}-\epsilon, \theta^{\prime}+\epsilon\right)$, therefore $\Delta^{r_{1}}\left(\theta^{\prime}, n\left(., \theta^{\prime}\right)\right)<0$. Note that this still holds for any $\epsilon \leq \bar{\epsilon}\left(r_{1}\right)$. We have established by the intermediate value theorem, the unique state $\theta^{*}$ where $\Delta^{r_{1}}\left(\theta^{*}, n\left(., \theta^{*}\right)\right)=0$.

\section{C.2 The identified threshold is an equilibrium}

Step 2 studies how the integral of net incentives $\Delta^{r_{1}}\left(\theta_{i}, n\left(., \theta^{*}\right)\right)$ varies with $i$ 's signal, $\theta_{i}$. Step 1 showed it is zero at $\theta_{i}=\theta^{*}$. Lemma 6 shows it is continuous in the signal $\theta_{i}$ and Lemma 7 shows that it is negative for all $\theta<\theta^{*}$ and positive for all $\theta>\theta^{*}$, thereby showing a threshold best response by investor $i$ at $\theta^{*}$ to all investors using the threshold strategy $\theta^{*}$.

Lemma 6. The function $\Delta^{r_{1}}\left(\theta_{i}, n\left(., \theta^{*}\left(r_{1}\right)\right)\right)$ is continuous in $\theta_{i}$.

Proof. $v(\theta)$ is bounded and has simple discontinuities, so the integral is continuous.

Lemma 7. There exists a $\bar{\epsilon}$ such that, for all $\epsilon \leq \bar{\epsilon}$, the function $\Delta\left(\theta_{i}, n\left(., \theta^{*}\left(r_{1}\right)\right)\right)$ starts negative and decreases in $\theta_{i}$, then bottoms out and increases until it is and remains positive.

Proof. The integral $\Delta^{r_{1}}\left(\theta_{i}, n\left(., \theta^{*}\left(r_{1}\right)\right)\right)$ starts constant at $-2 \epsilon \frac{u\left(r_{1}\right)}{r_{1}}$ when $\theta_{i}<\theta^{\prime}-2 \epsilon$. It decreases on the downward sliding portion of $v(\theta)$. It is clear that it bottoms out at the $\theta$ that achieves the following infimum: $\inf \left\{\theta_{i}: v\left(\theta_{i}-\epsilon\right)<v\left(\theta_{i}+\epsilon\right)\right\}$. (If this is not achieved because $\theta^{\prime}$ is close to the upper dominance region, then the same logic carries through, though.) After that point, as $\theta_{i}$ increases, the integral substitutes values of $v(\theta+\epsilon)$ which are higher than the $v\left(\theta_{i}-\epsilon\right)$ that get dropped out of the integral. Therefore, the integral increases. Straightforwardly, the integral is positive when $\theta_{i}>\bar{\theta}+\epsilon$.

\section{C.3 Uniqueness in general threshold strategies}

Step 3 shows that the symmetric threshold equilibrium is unique in all threshold strategies. Proof by contradiction. Suppose that there is an asymmetric threshold equilibrium. Then 
there are $\theta_{A} \neq \theta_{B}$ such that some investors withdraw at a signal below threshold $\theta_{A}$ and others withdraw below $\theta_{B}$. But at every signal in $\left[\theta_{A}, \theta_{B}\right]$, some investors withdraw, while others do not. So investors must be indifferent and the net incentive integral at each signal in this interval must be zero. In any threshold equilibrium, the proportion $n(\theta)$ weakly decreases in $\theta$. Since the integral of net incentives is zero at $\theta_{A}$, we have that $v\left(\theta_{A}-\epsilon\right)<0$ and $v\left(\theta_{A}+\epsilon\right)>0$. To see this, assume $v\left(\theta_{A}-\epsilon\right) \geq 0$, then $v(\theta)>0$ for all $\theta$ in $\left(\theta_{A}-\epsilon, \theta_{A}+\epsilon\right]$, and if $v\left(\theta_{A}+\epsilon\right) \leq 0$, then $v(\theta)<0$ for all $\theta$ in $\left[\theta_{A}-\epsilon, \theta_{A}+\epsilon\right)$. But then the integral of net incentives cannot be zero. Since $v\left(\theta_{A}+\epsilon\right)>0$, the combination of Lemma 1 and Lemma 3 ensure that $v($.$) increases at \theta_{A}+\epsilon$. Thus the integral of net incentives increases at signal $\theta_{A}$, since it drops negative values and adds positive ones. Contradiction.

\section{C.4 No non-threshold equilibrium in symmetric strategies}

The final step of the proof is to show that any equilibrium has to be in threshold strategies. This proof heavily builds on GP and we skip it here for brevity.

\section{Proof of Proposition 4}

We start with two lemmas that help us prove continuity of the withdrawal threshold $\theta^{*}(\epsilon)$ with respect to noise. The first lemma establishes that the optimal safe asset holdings do not depend directly on the noise $\epsilon$, but only indirectly through $n$ and $\theta$.

Lemma 8. For a given $n, y^{*}$ depends on $\epsilon$ through $\theta$.

Proof. First, we assume $\epsilon_{1} \neq \epsilon_{2}$. At the same $n$ and $\theta$, both problems have the same first-order condition 3. Thus, by strict concavity, $y^{*}\left(n, \theta, \epsilon_{1}\right)=y^{*}\left(n, \theta, \epsilon_{2}\right)$. And $y^{*}$ does not depend directly on $\epsilon$. Next, we show the dependence through $\theta(\epsilon)$. When $\theta\left(\epsilon_{1}\right) \neq \theta\left(\epsilon_{2}\right)$ and at the same $n$, the first-order condition 3 implies $\frac{u^{\prime}\left(y^{*}\left(\epsilon_{1}\right)\right)}{u^{\prime}\left[\frac{1-n r_{1}}{1-n} R-y^{*}\left(\epsilon_{1}\right)(R-1)\right]}=\frac{p\left(\theta\left(\epsilon_{1}\right)\right)(R-1)}{1-p\left(\theta\left(\epsilon_{1}\right)\right)}$. Hence, by strict concavity, $y^{*}\left(n, \theta\left(\epsilon_{1}\right)\right) \neq y^{*}\left(n, \theta\left(\epsilon_{2}\right)\right)$. 
The next lemma describes the relationship between $\theta^{*}\left(\epsilon_{1}\right)$ and $\theta^{*}\left(\epsilon_{2}\right)$ for different $\epsilon$.

Lemma 9. For all $\epsilon_{1} \neq \epsilon_{2}>0$, we have

$$
\begin{gathered}
\left.\int_{\lambda}^{\frac{1}{r_{1}}} p\left[\theta^{*}\left(\epsilon_{1}\right)+\epsilon_{1}\left(1-2 \frac{n-\lambda}{1-\lambda}\right)\right] u\left(\left(\frac{1-n r_{1}}{1-n}-y^{*}\right) R+y^{*}\right)+p\left[\theta^{*}\left(\epsilon_{1}\right)+\epsilon_{1}\left(1-2 \frac{n-\lambda}{1-\lambda}\right)\right]\right] u\left(y^{*}\right) d n= \\
\int_{\lambda}^{\frac{1}{r_{1}}} p\left[\theta^{*}\left(\epsilon_{2}\right)+\epsilon_{2}\left(1-2 \frac{n-\lambda}{1-\lambda}\right)\right] u\left(\left(\frac{1-n r_{1}}{1-n}-y^{*}\right) R+y^{*}\right)+p\left[\theta^{*}\left(\epsilon_{2}\right)+\epsilon_{2}\left(1-2 \frac{n-\lambda}{1-\lambda}\right)\right] u\left(y^{*}\right) d n
\end{gathered}
$$

Proof. At any $\epsilon$, an investor with signal $\theta^{*}(\epsilon)$ is indifferent between withdrawing and not withdrawing. Recall that $\hat{\theta}$ is the fundamental $\theta$ at which the bank is exactly insolvent $n\left(\theta, \theta^{*}\left(r_{1}\right)\right)=\frac{1}{r_{1}}$, where $\hat{\theta} \in\left(\theta^{*}-\epsilon, \theta^{*}+\epsilon\right)$. The expected utility of not withdrawing when the investor receives the threshold signal is $\frac{1}{2 \epsilon} \int_{\hat{\theta}}^{\theta^{*}+\epsilon} p(\theta) u\left(\left(\frac{1-n r_{1}}{1-n}-y^{*}\right) R+y^{*}\right)+(1-p(\theta)) u\left(y^{*}\right) d \theta$. The expected utility of withdrawing is $\int_{\theta^{*}-\epsilon}^{\hat{\theta}} \frac{u\left(r_{1}\right)}{n r_{1}} \frac{1}{2 \epsilon} d \theta+\int_{\hat{\theta}}^{\theta^{*}+\epsilon} u\left(r_{1}\right) \frac{1}{2 \epsilon} d \theta$. Thus:

$$
\int_{\hat{\theta}}^{\theta^{*}+\epsilon} p(\theta) u\left(\left(\frac{1-n r_{1}}{1-n}-y^{*}\right) R+y^{*}\right)+(1-p) u\left(y^{*}\right) d \theta=\int_{\theta^{*}-\epsilon}^{\hat{\theta}} \frac{u\left(r_{1}\right)}{n r_{1}} d \theta+\int_{\hat{\theta}}^{\theta^{*}+\epsilon} u\left(r_{1}\right) d \theta
$$

We use $n=\lambda+(1-\lambda)\left(\frac{1}{2}+\frac{\theta^{*}-\theta}{2 \epsilon}\right)$ to change the integration variables, $d \theta=-\frac{2 \epsilon}{1-\lambda} d n$, and Lemma 8 to get

$$
\begin{gathered}
\int_{\lambda}^{\frac{1}{r_{1}}} p\left(\theta^{*}+\epsilon\left(1-2 \frac{n-\lambda}{1-\lambda}\right)\right) u\left(\left(\frac{1-n r_{1}}{1-n}-y^{*}\right) R+y^{*}\right)+\left(1-p\left(\theta^{*}+\epsilon\left(1-2 \frac{n-\lambda}{1-\lambda}\right)\right)\right) u\left(y^{*}\right) d n \\
=\int_{\lambda}^{\frac{1}{r_{1}}} u\left(r_{1}\right) d n+\int_{\frac{1}{r_{1}}}^{1} \frac{u\left(r_{1}\right)}{r_{1} n} d n,
\end{gathered}
$$

where the right-hand side is independent of $\epsilon$. Rewriting yields equation (21).

Next, we show that the withdrawal threshold $\theta^{*}(\epsilon)$ is continuous in $\epsilon$. Proof by contradiction. Assume $\exists x>0$ at which $\theta^{*}(\epsilon)$ is not continuous. Then there exists a sequence $\left\{\epsilon_{m}\right\}$ with $\epsilon_{m}>0$ s.t. $\epsilon_{m} \rightarrow x$ but $\theta^{*}\left(\epsilon_{m}\right) \nrightarrow \theta^{*}(x) . \theta^{*}\left(\epsilon_{m}\right) \in[0,1]$ a sequence in a compact set, so it has a convergent subsequence with limit $\theta \neq \theta^{*}(x)$. Let $\left|\theta-\theta^{*}(x)\right|=\eta$. There exists $\bar{m}$ s.t. $\forall m>\bar{m},\left|\epsilon_{m}-x\right|<\delta$ but $\left|\theta^{*}\left(\epsilon_{m}\right)-\theta^{*}(x)\right|>\frac{\eta}{2}$. Assume $\theta>\theta^{*}(x)$-a similar argument holds for $\theta<\theta^{*}(x)$ - then $\theta\left(\epsilon_{m}\right)-\theta^{*}(x)>0 \forall m>\bar{m}$. But then by choosing $\epsilon_{m}$ close enough to $x, \exists \bar{m}$ (we abuse notation here by calling this new cutoff counter $\bar{m}$ again) s.t. $\forall m>\bar{m}, \theta\left(\epsilon_{m}\right)-\theta(x)-\left(1-2 \frac{n-\lambda}{1-\lambda}\right)\left(\epsilon_{m}-x\right)>\frac{\eta}{4}$ for all withdrawal proportions $\lambda \leq n \leq \frac{1}{r_{1}}$. By using Lemma 3, we show that the expected utility at $\theta\left(\epsilon_{m}\right)-\left(1-2 \frac{n-\lambda}{1-\lambda}\right) \epsilon_{m}$ 
is greater than at $\theta(x)-\left(1-2 \frac{n-\lambda}{1-\lambda}\right) x$ for all $n$. But then the integral of the expected utility across $n$, still preserves the same sign, which contradicts Lemma 9. In other words:

$$
\begin{gathered}
\left.\int_{\lambda}^{\frac{1}{r_{1}}} p\left[\theta^{*}\left(\epsilon_{m}\right)+\epsilon_{m}\left(1-2 \frac{n-\lambda}{1-\lambda}\right)\right] u\left(\left(\frac{1-n r_{1}}{1-n}-y^{*}\right) R+y^{*}\right)+p\left[\theta^{*}\left(\epsilon_{m}\right)+\epsilon_{m}\left(1-2 \frac{n-\lambda}{1-\lambda}\right)\right]\right] u\left(y^{*}\right) d n- \\
\int_{\lambda}^{\frac{1}{r_{1}}} p\left[\theta^{*}(x)+x\left(1-2 \frac{n-\lambda}{1-\lambda}\right)\right] u\left(\left(\frac{1-n r_{1}}{1-n}-y^{*}\right) R+y^{*}\right)+p\left[\theta^{*}(x)+x\left(1-2 \frac{n-\lambda}{1-\lambda}\right)\right] u\left(y^{*}\right) d n>0
\end{gathered}
$$

The contradiction with Lemma 9 completes the proof of the continuity with respect to noise.

We next prove that there is a unique limit of $\theta^{*}\left(\epsilon_{m}\right)$ for every noise sequence going to zero. $\theta^{*}\left(\epsilon_{m}\right)$ is in the compact set $[0,1]$, so it has a convergent subsequence for any sequence $\left\{\epsilon_{m}\right\}$ going to zero. We show that there cannot be two subsequential limits, thus proving the claim. The idea of the proof follows the proof for continuity. We sketch it here. Contrapositive, assume there are two subsequential limits. Then there are two sequences converging to those two different limits. One limit is greater than the other. But then we can find two elements along the two sequences, call them $x$ and $\epsilon_{m}$, close enough to each other (since they are close to zero) s.t. inequality 24 holds.

We now compute the unique limit $\theta$. We first note that the proof of Lemma 3 contains a discussion on why $y^{*}$ is continuous in $p$, which we will use here.

Let $g(n)=p\left(\theta^{*}\right) u\left[\frac{1-n r_{1}}{1-n} R-y^{*}(R-1)\right]+\left(1-p\left(\theta^{*}\right)\right) u\left(y^{*}\right)$. Let $g^{\epsilon}(n)=p\left(\theta^{*}(\epsilon)+\epsilon[1-\right.$ $\left.\left.2 \frac{n-\lambda}{1-\lambda}\right]\right) u\left[\frac{1-n r_{1}}{1-n} R-y^{*}(R-1)\right]+\left(1-p\left(\theta^{*}(\epsilon)+\epsilon\left[1-2 \frac{n-\lambda}{1-\lambda}\right]\right)\right) u\left(y^{*}\right)$. We direct the reader to Lemma 8 to point out that $y^{*}$ depends only indirectly on $\epsilon$ through $\theta=\theta^{*}(\epsilon)+\epsilon\left[1-2 \frac{n-\lambda}{1-\lambda}\right]$. By continuity of $p(),. u($.$) , and y^{*}$ in $\theta, g^{\epsilon} \rightarrow g$ point-wise. Taking the limits of equation $(22):$

$$
\begin{aligned}
\lim _{\epsilon \rightarrow 0} \int_{\lambda}^{\frac{1}{r_{1}}} p\left(\theta^{*}+\epsilon\left(1-2 \frac{n-\lambda}{1-\lambda}\right)\right) & u\left(\left(\frac{1-n r_{1}}{1-n}-y^{*}\right) R+y^{*}\right)+\left(1-p\left(\theta^{*}+\epsilon\left(1-2 \frac{n-\lambda}{1-\lambda}\right)\right)\right) u\left(y^{*}\right) d n \\
= & \int_{\lambda}^{\frac{1}{r_{1}}} u\left(r_{1}\right) d n+\int_{\frac{1}{r_{1}}}^{1} \frac{u\left(r_{1}\right)}{r_{1} n} d n
\end{aligned}
$$


We use the dominated convergence theorem to get

$$
\begin{aligned}
& \int_{\lambda}^{\frac{1}{r_{1}}} \lim _{\epsilon \rightarrow 0} p\left(\theta^{*}+\epsilon\left(1-2 \frac{n-\lambda}{1-\lambda}\right)\right) u\left(\left(\frac{1-n r_{1}}{1-n}-y^{*}\right) R+y^{*}\right)+\lim _{\epsilon \rightarrow 0}\left(1-p\left(\theta^{*}+\epsilon\left(1-2 \frac{n-\lambda}{1-\lambda}\right)\right)\right) u\left(y^{*}\right) d n \\
& =\int_{\lambda}^{\frac{1}{r_{1}}} u\left(r_{1}\right) d n+\int_{\frac{1}{r_{1}}}^{1} \frac{u\left(r_{1}\right)}{r_{1} n} d n \\
& \int_{\lambda}^{\frac{1}{r_{1}}} p\left(\theta^{*}\right) u\left(\left(\frac{1-n r_{1}}{1-n}-y^{*}\right) R+y^{*}\right)+\left(1-p\left(\theta^{*}\right)\right) u\left(y^{*}\right) d n=\int_{\lambda}^{\frac{1}{r_{1}}} u\left(r_{1}\right) d n+\int_{\frac{1}{r_{1}}}^{1} \frac{u\left(r_{1}\right)}{r_{1} n} d n,
\end{aligned}
$$

where $y^{*}$ in the last equation is $y^{*}=y^{*}\left(p\left(\theta^{*}\right), n\right)$. Simplifying yields:

$$
\begin{aligned}
& p\left(\theta^{*}\right) \int_{\lambda}^{\frac{1}{r_{1}}} u\left(\left(\frac{1-n r_{1}}{1-n}-y^{*}\right) R+y^{*}\right) d n+\left(1-p\left(\theta^{*}\right)\right) \int_{\lambda}^{\frac{1}{r_{1}}} u\left(y^{*}\right) d n=\int_{\lambda}^{\frac{1}{r_{1}}} u\left(r_{1}\right) d n+\int_{\frac{1}{r_{1}}}^{1} \frac{u\left(r_{1}\right)}{r_{1} n} d n \\
& p\left(\theta^{*}\right)=\int_{\lambda}^{\frac{1}{r_{1}}} u\left(r_{1}\right) d n+\int_{\frac{1}{r_{1}}}^{1} \frac{u\left(r_{1}\right)}{r_{1} n} d n-\int_{\lambda}^{\frac{1}{r_{1}}} u\left(y^{*}\right) d n /\left(\int_{\lambda}^{\frac{1}{r_{1}}} u\left(\left(\frac{1-n r_{1}}{1-n}-y^{*}\right) R+y^{*}\right) d n-\int_{\lambda}^{\frac{1}{r_{1}}} u\left(y^{*}\right) d n\right) \\
& p\left(\theta^{*}\right)=\frac{\int_{\lambda}^{\frac{1}{r_{1}}} u\left(r_{1}\right) d n+\int_{\frac{1}{r_{1}}}^{1} \frac{u\left(r_{1}\right)}{r_{1} n} d n-\int_{\lambda}^{\frac{1}{r_{1}}} u\left(y^{*}\right) d n}{\int_{\lambda}^{\frac{1}{r_{1}}} u\left(\left(\frac{1-n r_{1}}{1-n}-y^{*}\right) R+y^{*}\right) d n-\int_{\lambda}^{\frac{1}{r_{1}}} u\left(y^{*}\right) d n} .
\end{aligned}
$$

\section{E Proof of Proposition 5}

Rewriting equation (5) and taking the derivative yields

$$
\begin{aligned}
& \int_{n=\lambda}^{\frac{1}{r_{1}}} p\left(\theta^{*}\right) u\left(\frac{1-n r_{1}}{1-n} R-(R-1) y^{*}\left(r_{1}\right)\right)+\left(1-p\left(\theta^{*}\right)\right) u\left(y^{*}\left(r_{1}\right)\right) d n \\
& +r_{1} \frac{\partial}{\partial r_{1}} \int_{n=\lambda}^{\frac{1}{r_{1}}} p\left(\theta^{*}\right) u\left(\frac{1-n r_{1}}{1-n} R-(R-1) y^{*}\left(r_{1}\right)\right)+\left(1-p\left(\theta^{*}\right)\right) u\left(y^{*}\left(r_{1}\right)\right) d n \\
& =u^{\prime}\left(r_{1}\right)\left[1-\lambda r_{1}+\ln \left(r_{1}\right)\right]+\left(u\left(r_{1}\right) / r_{1}\right)\left(1-\lambda r_{1}\right), \\
& \int_{n=\lambda}^{\frac{1}{r_{1}}} p\left(\theta^{*}\right) u\left(\frac{1-n r_{1}}{1-n} R-(R-1) y^{*}\left(r_{1}\right)\right)+\left(1-p\left(\theta^{*}\right)\right) u\left(y^{*}\left(r_{1}\right)\right) d n \\
& \Leftrightarrow \quad \begin{aligned}
\quad & +r_{1} \int_{n=\lambda}^{\frac{1}{r_{1}}} p^{\prime}\left(\theta^{*}\right) \frac{\partial \theta^{*}}{\partial r_{1}} u\left(\frac{1-n r_{1}}{1-n} R-(R-1) y^{*}\left(r_{1}\right)\right)-p^{\prime}\left(\theta^{*}\right) \frac{\partial \theta^{*}}{\partial r_{1}} u\left(y^{*}\left(r_{1}\right)\right) d n \\
+ & r_{1} \int_{n=\lambda}^{\frac{1}{r_{1}}} p\left(\theta^{*}\right) \frac{\partial}{\partial r_{1}} u\left(\frac{1-n r_{1}}{1-n} R-(R-1) y^{*}\left(r_{1}\right)\right)+\left(1-p\left(\theta^{*}\right)\right) \frac{\partial}{\partial r_{1}} u\left(y^{*}\left(r_{1}\right)\right) d n
\end{aligned} \\
& =u^{\prime}\left(r_{1}\right)\left[1-\lambda r_{1}+\ln \left(r_{1}\right)\right]+\left(u\left(r_{1}\right) / r_{1}\right)\left(1-\lambda r_{1}\right) .
\end{aligned}
$$


Thus:

$$
\begin{gathered}
\frac{\partial \theta^{*}}{\partial r_{1}} p^{\prime}\left(\theta^{*}\right) r_{1} \int_{\lambda}^{\frac{1}{r_{1}}} u\left(\frac{1-n r_{1}}{1-n} R-(R-1) y^{*}\right)-u\left(y^{*}\right) d n= \\
-r_{1} \int_{n=\lambda}^{\frac{1}{r_{1}}} p\left(\theta^{*}\right) \frac{\partial}{\partial r_{1}} u\left(\frac{1-n r_{1}}{1-n} R-(R-1) y^{*}\left(r_{1}\right)\right)+\left(1-p\left(\theta^{*}\right)\right) \frac{\partial}{\partial r_{1}} u\left(y^{*}\left(r_{1}\right)\right) d n \\
-\int_{n=\lambda}^{\frac{1}{r_{1}}} p\left(\theta^{*}\right) u\left(\frac{1-n r_{1}}{1-n} R-(R-1) y^{*}\left(r_{1}\right)\right)+\left(1-p\left(\theta^{*}\right)\right) u\left(y^{*}\left(r_{1}\right)\right) d n \\
+u^{\prime}\left(r_{1}\right)\left[1-\lambda r_{1}+\ln \left(r_{1}\right)\right]+\left(u\left(r_{1}\right) / r_{1}\right)\left(1-\lambda r_{1}\right)
\end{gathered}
$$

In words, the left-hand side of equation (29) is equal to $-r_{1}$ multiplied by the expected derivative minus the expected utility and the last two positive terms. This differs from GP's equation because the expected utility and the expected derivative differ from GP's.

The last two terms are positive: $p^{\prime}()>$.0 , the difference $u\left(\frac{1-n r_{1}}{1-n} R-(R-1) y^{*}\right)-$ $u\left(y^{*}\right)>0$ for an interior $y^{*}$, so we have $\frac{\partial \theta^{*}}{\partial r_{1}}>0$ if the negative of the expected derivative minus the expected utility is positive, which happens for $-r_{1} \int_{n=\lambda}^{\frac{1}{r_{1}}} p\left(\theta^{*}\right) \frac{\partial}{\partial r_{1}} u\left(\frac{1-n r_{1}}{1-n} R-\right.$ $\left.(R-1) y^{*}\left(r_{1}\right)\right)+\left(1-p\left(\theta^{*}\right)\right) \frac{\partial}{\partial r_{1}} u\left(y^{*}\left(r_{1}\right)\right) d n-\int_{n=\lambda}^{\frac{1}{r_{1}}} p\left(\theta^{*}\right) u\left(\frac{1-n r_{1}}{1-n} R-(R-1) y^{*}\left(r_{1}\right)\right)+(1-$ $\left.p\left(\theta^{*}\right)\right) u\left(y^{*}\left(r_{1}\right)\right) d n>0$. Focusing on the expected derivative with respect to $r_{1}$, we express it as a derivative with respect to $n$ in order to use integration by parts (see also GP):

$$
\begin{aligned}
\frac{\partial}{\partial r_{1}} u\left(\frac{1-n r_{1}}{1-n} R-(R-1) y^{*}\left(r_{1}\right)\right) & =u^{\prime}\left(\frac{1-n r_{1}}{1-n} R-(R-1) y^{*}\left(r_{1}\right)\right)\left(-\frac{n R}{1-n}-(R-1) \frac{\partial y^{*}}{\partial r_{1}}\right) \\
\frac{\partial}{\partial r_{1}} u\left(y^{*}\right) & =u^{\prime}\left(y^{*}\right) \frac{\partial y^{*}}{\partial r_{1}} .
\end{aligned}
$$

Thus, $p\left(\theta^{*}\right) \frac{\partial}{\partial r_{1}} u\left(\frac{1-n r_{1}}{1-n} R-(R-1) y^{*}\left(r_{1}\right)\right)+\left(1-p\left(\theta^{*}\right)\right) \frac{\partial}{\partial r_{1}} u\left(y^{*}\left(r_{1}\right)\right)=-p\left(\theta^{*}\right) u^{\prime}\left(\left(\frac{1-n r_{1}}{1-n} R-\right.\right.$ $\left.\left.(R-1) y^{*}\left(r_{1}\right)\right)\right)\left(\frac{n R}{1-n}\right)-p\left(\theta^{*}\right)(R-1) \frac{\partial y^{*}}{\partial r_{1}} u^{\prime}\left(\frac{1-n r_{1}}{1-n} R-(R-1) y^{*}\left(r_{1}\right)\right)+\left(1-p\left(\theta^{*}\right)\right) \frac{\partial y^{*}}{\partial r_{1}} u^{\prime}\left(y^{*}\right)$. Collecting terms yields $p\left(\theta^{*}\right) \frac{\partial}{\partial r_{1}} u\left(\frac{1-n r_{1}}{1-n} R-(R-1) y^{*}\left(r_{1}\right)\right)+\left(1-p\left(\theta^{*}\right)\right) \frac{\partial}{\partial r_{1}} u\left(y^{*}\left(r_{1}\right)\right)=$ $\left.-p\left(\theta^{*}\right) u^{\prime}\left(\left(\frac{1-n r_{1}}{1-n} R-(R-1) y^{*}\left(r_{1}\right)\right)\right) \frac{n R}{1-n}\right)-\frac{\partial y^{*}}{\partial r_{1}}\left[p\left(\theta^{*}\right)(R-1) u^{\prime}\left(\frac{1-n r_{1}}{1-n} R-(R-1) y^{*}\left(r_{1}\right)\right)-\right.$ 
$\left.\left(1-p\left(\theta^{*}\right)\right) u^{\prime}\left(y^{*}\right)\right]$. Using the first-order condition for $y^{*}$ makes the last term null; we get

$$
\begin{aligned}
& p\left(\theta^{*}\right) \frac{\partial}{\partial r_{1}} u\left(\frac{1-n r_{1}}{1-n} R-(R-1) y^{*}\left(r_{1}\right)\right)+\left(1-p\left(\theta^{*}\right)\right) \frac{\partial}{\partial r_{1}} u\left(y^{*}\left(r_{1}\right)\right)=\cdots \\
& =-u^{\prime}\left(\left(\frac{1-n r_{1}}{1-n} R-(R-1) y^{*}\left(r_{1}\right)\right)\right) p\left(\theta^{*}\right)\left(\frac{n R}{1-n}\right) \\
& p\left(\theta^{*}\right) \frac{\partial}{\partial n} u\left(\frac{1-n r_{1}}{1-n} R-(R-1) y^{*}\left(r_{1}\right)\right)+\left(1-p\left(\theta^{*}\right)\right) \frac{\partial}{\partial n} u\left(y^{*}\left(r_{1}\right)\right)=\cdots \\
& =-p\left(\theta^{*}\right) u^{\prime}\left(\left(\frac{1-n r_{1}}{1-n} R-(R-1) y^{*}\left(r_{1}\right)\right)\right)\left(\frac{R\left(r_{1}-1\right)}{(1-n)^{2}}\right) \\
\Rightarrow \quad & \frac{p\left(\theta^{*}\right) \frac{\partial}{\partial r_{1}} u\left(\frac{1-n r_{1}}{1-n} R-(R-1) y^{*}\left(r_{1}\right)\right)+\left(1-p\left(\theta^{*}\right)\right) \frac{\partial}{\partial r_{1}} u\left(y^{*}\left(r_{1}\right)\right)}{p\left(\theta^{*}\right) \frac{\partial}{\partial n} u\left(\frac{1-n r_{1}}{1-n} R-(R-1) y^{*}\left(r_{1}\right)\right)+\left(1-p\left(\theta^{*}\right)\right) \frac{\partial}{\partial n} u\left(y^{*}\left(r_{1}\right)\right)}=\frac{n(1-n)}{r_{1}-1}
\end{aligned}
$$

Using equation (33), the second term of equation (29) becomes

$$
\begin{aligned}
& -r_{1} \int_{n=\lambda}^{\frac{1}{r_{1}}} p\left(\theta^{*}\right) \frac{\partial}{\partial r_{1}} u\left(\frac{1-n r_{1}}{1-n} R-(R-1) y^{*}\left(r_{1}\right)\right)+\left(1-p\left(\theta^{*}\right)\right) \frac{\partial}{\partial r_{1}} u\left(y^{*}\left(r_{1}\right)\right) d n=\cdots \\
& =-\frac{r_{1}}{r_{1}-1} \int_{n=\lambda}^{\frac{1}{r_{1}}} p\left(\theta^{*}\right) n(1-n) \frac{\partial}{\partial n} u\left(\frac{1-n r_{1}}{1-n} R-(R-1) y^{*}\left(r_{1}\right)\right)+\left(1-p\left(\theta^{*}\right)\right) n(1-n) \frac{\partial}{\partial r_{1}} u\left(y^{*}\left(r_{1}\right)\right) d n
\end{aligned}
$$

Integrating by parts the two terms (we do only the harder term; the other one is similar), let $u=n(1-n)$ and $d v=\frac{\partial u}{\partial n}\left(\frac{1-n r_{1}}{1-n} R-(R-1) y^{*}\right)$, then $d u=(1-2 n) d n$ and $v=$ $u\left(\frac{1-n r_{1}}{1-n} R-(R-1) y^{*}\right)$. We get $-p\left(\theta^{*}\right) \frac{r_{1}}{r_{1}-1}\left[-\lambda(1-\lambda) u\left(\frac{1-\lambda r_{1}}{1-\lambda} R-(R-1) y^{*}(\lambda)\right)-\int_{n=\lambda}^{\frac{1}{r_{1}}}(1-\right.$ $\left.2 n) u\left(\frac{1-r_{1} n}{1-n} R-(R-1) y^{*}\right) d n\right]$ and $-\left(1-p\left(\theta^{*}\right)\right) \frac{r_{1}}{r_{1}-1}\left[-\lambda(1-\lambda) u\left(y^{*}(\lambda)\right)-\int_{n=\lambda}^{\frac{1}{r_{1}}}(1-2 n) u\left(y^{*}\right) d n\right]$. Thus:

$$
\begin{gathered}
-r_{1} \int_{n=\lambda}^{\frac{1}{r_{1}}} p\left(\theta^{*}\right) \frac{\partial}{\partial r_{1}} u\left(\frac{1-n r_{1}}{1-n} R-(R-1) y^{*}\left(r_{1}\right)\right)+\left(1-p\left(\theta^{*}\right)\right) \frac{\partial}{\partial r_{1}} u\left(y^{*}\left(r_{1}\right)\right) d n= \\
-p\left(\theta^{*}\right) \frac{r_{1}}{r_{1}-1}\left[-\lambda(1-\lambda) u\left(\frac{1-\lambda r_{1}}{1-\lambda} R-(R-1) y^{*}(\lambda)\right)-\int_{n=\lambda}^{\frac{1}{r_{1}}}(1-2 n) u\left(\frac{1-r_{1} n}{1-n} R-(R-1) y^{*}\right) d n\right] \\
-\left(1-p\left(\theta^{*}\right)\right) \frac{r_{1}}{r_{1}-1}\left[-\lambda(1-\lambda) u\left(y^{*}(\lambda)\right)-\int_{n=\lambda}^{\frac{1}{r_{1}}}(1-2 n) u\left(y^{*}\right) d n\right]
\end{gathered}
$$

Taken together, the two terms of equation (29) yield

$$
\begin{gathered}
p\left(\theta^{*}\right) \frac{r_{1}}{r_{1}-1} \lambda(1-\lambda) u\left(\frac{1-\lambda r_{1}}{1-\lambda} R-(R-1) y^{*}(\lambda)\right)+\frac{p\left(\theta^{*}\right)}{r_{1}-1} \int_{n=\lambda}^{\frac{1}{r_{1}}}\left(1-2 n r_{1}\right) u\left(\frac{1-n r_{1}}{1-n} R-(R-1) y^{*}\right) d n \\
\left(1-p\left(\theta^{*}\right)\right) \frac{r_{1}}{r_{1}-1} \lambda(1-\lambda) u\left(y^{*}(\lambda)\right)+\frac{1-p\left(\theta^{*}\right)}{r_{1}-1} \int_{n=\lambda}^{\frac{1}{r_{1}}}\left(1-2 n r_{1}\right) u\left(y^{*}\right) d n
\end{gathered}
$$

It remains to be shown that expression (36) is positive. A picture (below) helps with this 
step. The picture could be drawn in two ways, and in both cases we get the desired result. If $1-2 \lambda r_{1}<0$, then $1-2 n r_{1}$ never hits zero on the domain. If it is positive, it does hit zero. In both cases $1-2 n r_{1}$ evaluated at the midpoint of the domain segment $\left(\frac{\frac{1}{r_{1}}+\lambda}{2}\right)$ is negative. We will assume it does not hit zero, the other case follows similarly. Note that there are two triangles: one to the left and one to the right of the dotted line. These two triangles are congruent. Since $u($.$) is decreasing, substituting \frac{\frac{1}{r_{1}}+\lambda}{2}$ instead of $n$ inside the integral just shifts weights on different $u($.$) values inside the integral. Now note that the blue line$ is a plot of the line $1-2 n r_{1}$, while the red line is the constant function at $1-2 r_{1} \frac{\frac{1}{r_{1}}+\lambda}{2}$.

From Lemma 1 , we have that $\frac{1-n r_{1}}{1-n} R-(R-1) y^{*}$ and $y^{*}$ are both decreasing in $n$. Because $u($.$) is decreasing, this exchange shifts weight from higher-valued u()$ s to lowervalued ones. Therefore, we have $\frac{p\left(\theta^{*}\right)}{r_{1}-1} \int_{n=\lambda}^{\frac{1}{r_{1}}}\left(1-2 n r_{1}\right) u\left(\frac{1-n r_{1}}{1-n} R-(R-1) y^{*}\right) d n>\frac{p\left(\theta^{*}\right)}{r_{1}-1} \int_{n=\lambda}^{\frac{1}{r_{1}}}(1-$ $\left.2\left(\frac{\frac{1}{r_{1}}+\lambda}{2}\right) r_{1}\right) u\left(\frac{1-n r_{1}}{1-n} R-(R-1) y^{*}\right) d n=-\frac{\lambda r_{1} p\left(\theta^{*}\right)}{r_{1}-1} \int_{n=\lambda}^{\frac{1}{r_{1}}} u\left(\frac{1-n r_{1}}{1-n} R-(R-1) y^{*}\right) d n$. And also: $\frac{p\left(\theta^{*}\right)}{r_{1}-1} \int_{n=\lambda}^{\frac{1}{r_{1}}}\left(1-2 n r_{1}\right) u\left(y^{*}\right) d n>\frac{p\left(\theta^{*}\right)}{r_{1}-1} \int_{n=\lambda}^{\frac{1}{r_{1}}}\left(1-2\left(\frac{\frac{1}{r_{1}}+\lambda}{2}\right) r_{1}\right) u\left(y^{*}\right) d n=-\frac{\lambda r_{1} p\left(\theta^{*}\right)}{r_{1}-1} \int_{n=\lambda}^{\frac{1}{r_{1}}} u\left(y^{*}\right) d n$.

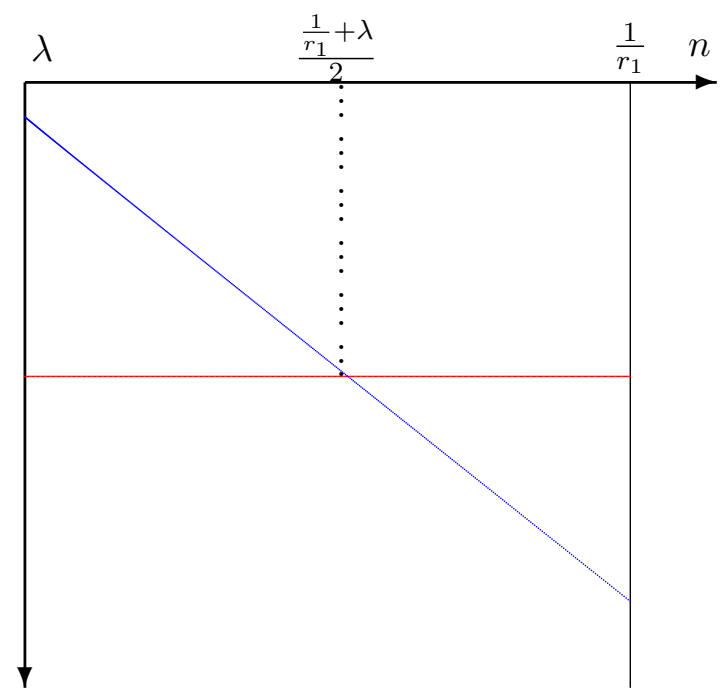

Moreover, since from Lemma $1, \frac{1-n r_{1}}{1-n} R-(R-1) y^{*}$ and $y^{*}$ are both decreasing in $n$ and $u($.$) is decreasing, \left(\frac{1}{r_{1}}-\lambda\right) u\left(\frac{1-\lambda r_{1}}{1-\lambda} R-(R-1) y^{*}(\lambda)\right)>\int_{n=\lambda}^{\frac{1}{r_{1}}} u\left(\frac{1-n r_{1}}{1-n} R-(R-1) y^{*}\right) d n$. We get that $-\frac{\lambda r_{1} p\left(\theta^{*}\right)}{r_{1}-1} \int_{n=\lambda}^{\frac{1}{r_{1}}} u\left(\frac{1-n r_{1}}{1-n} R-(R-1) y^{*}\right) d n>-p\left(\theta^{*}\right) \frac{r_{1}}{r_{1}-1} \lambda\left(\frac{1}{r_{1}}-\lambda\right) u\left(\frac{1-\lambda r_{1}}{1-\lambda} R-(R-1) y^{*}\right)$. Similarly, $\left(\frac{1}{r_{1}}-\lambda\right) u\left(y^{*}(\lambda)\right)>\int_{n=\lambda}^{\frac{1}{r_{1}}} u\left(y^{*}\right) d n$, so $-\frac{\lambda r_{1} p\left(\theta^{*}\right)}{r_{1}-1} \int_{n=\lambda}^{\frac{1}{r_{1}}} u\left(y^{*}\right) d n>-p\left(\theta^{*}\right) \frac{r_{1}}{r_{1}-1} \lambda\left(\frac{1}{r_{1}}-\right.$ 
$\lambda) u\left(y^{*}(\lambda)\right)$. Next, looking at the sum on the top, we find

$$
\begin{gathered}
p\left(\theta^{*}\right) \frac{r_{1}}{r_{1}-1} \lambda(1-\lambda) u\left(\frac{1-\lambda r_{1}}{1-\lambda} R-(R-1) y^{*}(\lambda)\right)+\frac{p\left(\theta^{*}\right)}{r_{1}-1} \int_{n=\lambda}^{\frac{1}{r_{1}}}\left(1-2 n r_{1}\right) u\left(\frac{1-n r_{1}}{1-n} R-(R-1) y^{*}\right) d n> \\
p\left(\theta^{*}\right) \frac{r_{1}}{r_{1}-1} \lambda(1-\lambda) u\left(\frac{1-\lambda r_{1}}{1-\lambda} R-(R-1) y^{*}(\lambda)\right)-p\left(\theta^{*}\right) \frac{r_{1}}{r_{1}-1} \lambda\left(\frac{1}{r_{1}}-\lambda\right) u\left(\frac{1-\lambda r_{1}}{1-\lambda} R-(R-1) y^{*}(\lambda)\right) \quad \text { and } \\
p\left(\theta^{*}\right) \frac{r_{1}}{r_{1}-1} \lambda(1-\lambda) u\left(\frac{1-\lambda r_{1}}{1-\lambda} R-(R-1) y^{*}(\lambda)\right)+\frac{p\left(\theta^{*}\right)}{r_{1}-1} \int_{n=\lambda}^{\frac{1}{r_{1}}}\left(1-2 n r_{1}\right) u\left(\frac{1-n r_{1}}{1-n} R-(R-1) y^{*}\right) d n> \\
p\left(\theta^{*}\right) \lambda u\left(\frac{1-\lambda r_{1}}{1-\lambda} R-(R-1) y^{*}(\lambda)\right)>0
\end{gathered}
$$

Similarly, $p\left(\theta^{*}\right) \frac{r_{1}}{r_{1}-1} \lambda(1-\lambda) u\left(y^{*}(\lambda)\right)+\frac{p\left(\theta^{*}\right)}{r_{1}-1} \int_{n=\lambda}^{\frac{1}{r_{1}}}\left(1-2 n r_{1}\right) u\left(y^{*}\right) d n>p\left(\theta^{*}\right) \lambda u\left(y^{*}(\lambda)\right)>0$, which completes our proof.

\section{F $\quad$ Proof of Proposition 6}

Proof by contradiction. Assume that $\theta^{*} \geq \theta_{G P}^{*}$. Fix a withdrawal proportion $n: \lambda \leq$ $n \leq \frac{1}{r_{1}}$, where $n$ determines the resources left for the remaining patient investors. Under $p\left(\theta^{*}\right)$ and without insurance, these resources are all invested in the project and yield $p\left(\theta^{*}\right) u\left(\frac{1-n r_{1}}{1-n} R\right)$. With insurance, in contrast, these resources yield $p\left(\theta^{*}\right) u\left(\frac{1-n r_{1}}{1-n} R-(R-\right.$ 1) $\left.y^{*}\left(r_{1}\right)\right)+\left(1-p\left(\theta^{*}\right)\right) u\left(y^{*}\left(r_{1}\right)\right)$. Since investors are risk averse and marginal utility is high enough at zero, we have $y^{*}\left(r_{1}\right)>0$ and $p\left(\theta^{*}\right) u\left(\frac{1-n r_{1}}{1-n} R-(R-1) y^{*}\left(r_{1}\right)\right)+(1-$ $\left.p\left(\theta^{*}\right)\right) u\left(y^{*}\left(r_{1}\right)\right)>p\left(\theta^{*}\right) u\left(\frac{1-n r_{1}}{1-n} R\right)$. Note that $\theta^{*} \geq \theta_{G P}^{*}$ implies that $p\left(\theta^{*}\right) \geq p\left(\theta_{G P}^{*}\right)$ and, therefore, $\int_{n=\lambda}^{\frac{1}{r_{1}}} p\left(\theta^{*}\right) u\left(\frac{1-n r_{1}}{1-n} R\right) d n \geq \int_{n=\lambda}^{\frac{1}{r_{1}}} p\left(\theta_{G P}^{*}\right) u\left(\frac{1-n r_{1}}{1-n} R\right) d n$. This would imply $\int_{n=\lambda}^{\frac{1}{r_{1}}} p\left(\theta^{*}\right)$ $u\left(\frac{1-n r_{1}}{1-n} R-(R-1) y^{*}\left(r_{1}\right)\right)+\left(1-p\left(\theta^{*}\right)\right) u\left(y^{*}\left(r_{1}\right)\right) d n>\int_{n=\lambda}^{\frac{1}{r_{1}}} p\left(\theta^{*}\right) u\left(\frac{1-n r_{1}}{1-n} R\right) d n \geq \int_{n=\lambda}^{\frac{1}{r_{1}}} p\left(\theta_{G P}^{*}\right)$ $u\left(\frac{1-n r_{1}}{1-n} R\right) d n=\frac{u\left(r_{1}\right)}{r_{1}}\left(1-\lambda r_{1}+\ln \left(r_{1}\right)\right)$, a contradiction. This completes the proof.

\section{G Proof of Propositions 7 and 8}

Fix any $\theta>\theta^{*}$. Recall that $\theta^{*}<\theta_{G P}^{*}$. When no patient investor withdraws, an investor with a signal above the equilibrium threshold strictly prefers to wait. At $n=\lambda, v(\theta, \lambda)>0$, so $(1-p(\theta)) u\left(y^{*}\right)+p(\theta) u\left(\left(\frac{1-n r_{1}}{1-n}-y^{*}\right) R+y^{*}\right)>u\left(r_{1}\right)>\frac{u\left(r_{1}\right)}{r_{1}}$, which follows from $r_{1}>1$. 
But then by taking a convex combination of the two terms greater than $\frac{u\left(r_{1}\right)}{r_{1}}$, the result is still greater than $\frac{u\left(r_{1}\right)}{r_{1}}:(1-\lambda)\left[(1-p(\theta)) u\left(y^{*}\right)+p(\theta) u\left(\left(\frac{1-n r_{1}}{1-n}-y^{*}\right) R+y^{*}\right)\right]+\lambda u\left(r_{1}\right)>\frac{u\left(r_{1}\right)}{r_{1}}$. But then: $\int_{\theta^{*}}^{\theta_{G P}^{*}}(1-\lambda)\left[(1-p(\theta)) u\left(y^{*}\right)+p(\theta) u\left(\left(\frac{1-n r_{1}}{1-n}-y^{*}\right) R+y^{*}\right)\right]+\lambda u\left(r_{1}\right)>\frac{u\left(r_{1}\right)}{r_{1}}\left(\theta_{G P}^{*}-\theta^{*}\right)$. Therefore: $\frac{u\left(r_{1}\right)}{r_{1}} \theta^{*}+\int_{\theta^{*}}^{\theta_{G}^{*}} \lambda u\left(r_{1}\right)+(1-\lambda)\left[(1-p(\theta)) u\left(y^{*}\right)+p(\theta) u\left(\left(\frac{1-n r_{1}}{1-n}-y^{*}\right) R+y^{*}\right)\right] d \theta>$ $\frac{u\left(r_{1}\right)}{r_{1}} \theta_{G P}^{*}$. Next, since $\int_{\theta_{G P}^{*}\left(r_{1}\right)}^{1} \lambda u\left(r_{1}\right)+(1-\lambda)\left[(1-p(\theta)) u\left(y^{*}\right)+p(\theta) u\left(\left(\frac{1-n r_{1}}{1-n}-y^{*}\right) R+y^{*}\right)\right] d \theta>$ $\int_{\theta_{G P}^{*}\left(r_{1}\right)}^{1} \lambda u\left(r_{1}\right)+(1-\lambda) p(\theta) u\left(\frac{1-\lambda r_{1}}{1-\lambda} R\right) d \theta$ and adding the inequality to the one before, we get $\frac{u\left(r_{1}\right)}{r_{1}} \theta^{*}+\lambda\left(1-\theta^{*}\right) u\left(r_{1}\right)+(1-\lambda) \int_{\theta^{*}}^{1} p(\theta) u\left(\frac{1-\lambda r_{1}}{1-\lambda} R-(R-1) y^{*}\right)+(1-p(\theta)) u\left(y^{*}\right) d \theta>$ $\frac{u\left(r_{1}\right)}{r_{1}} \theta_{G P}^{*}+\lambda\left(1-\theta_{G P}^{*}\right) u\left(r_{1}\right)+(1-\lambda) u\left(\frac{1-\lambda r_{1}}{1-\lambda} R\right) \int_{\theta_{G P}^{*}}^{1} p(\theta) d \theta$. This completes the first proof.

Finally, we need to show $E U\left(r_{1}^{*}\right) \geq E U\left(r_{1 G P}^{*}\right)>E U_{G P}\left(r_{1 G P}^{*}\right)$. The first inequality follows from the optimality of $r_{1}^{*}$. The second inequality follows from the fact that allowing for safe assets raises expected utility in the subgame defined by $r_{1 G P}^{*}$.

\section{H Proof of Proposition 9}

This proof uses the concavity of the objective function in equation (7). For comparison with the objective function and its first-order condition, we state the equivalent expressions in GP here:

$$
\begin{gathered}
\lim _{\substack{\theta \rightarrow 1 \\
\epsilon \rightarrow 0}} E U_{G P}\left(r_{1}\right)=\frac{u\left(r_{1}\right)}{r_{1}} \theta_{G P}^{*}+\lambda\left(1-\theta_{G P}^{*}\right) u\left(r_{1}\right)+(1-\lambda) u\left(\frac{1-\lambda r_{1}}{1-\lambda} R\right) \int_{\theta_{G P}^{*}}^{1} p(\theta) d \theta . \\
\lambda\left(1-\theta_{G P}^{*}\right) u^{\prime}\left(r_{1}\right)=\frac{u\left(r_{1}\right)-u^{\prime}\left(r_{1}\right) r_{1}}{r_{1}^{2}} \theta_{G P}^{*}+\lambda R \int_{\theta_{G P}^{*}}^{1} p(\theta) u^{\prime}\left(\frac{1-\lambda r_{1}}{1-\lambda} R\right) d \theta \\
+\frac{\partial \theta_{G P}^{*}}{\partial r_{1}}\left[\lambda u\left(r_{1}\right)+(1-\lambda) p\left(\theta_{G P}^{*}\right) u\left(\frac{1-\lambda r_{1}}{1-\lambda} R\right)-\frac{u\left(r_{1}\right)}{r_{1}}\right]
\end{gathered}
$$

which defines bank liquidity provision without safe asset holdings, $r_{1, G P}^{*}$. One can show that the marginal expected utility (equation (8)) is positive when evaluated at $r_{1, G P}^{*}$. The concavity of the objective function then implies $r_{1}^{*}>r_{1, G P}^{*}$. 